\title{
Differential c-Fos Expression in Cholinergic, Monoaminergic, and GABAergic Cell Groups of the Pontomesencephalic Tegmentum after Paradoxical Sleep Deprivation and Recovery
}

\author{
Karen J. Maloney, Lynda Mainville, and Barbara E. Jones \\ Department of Neurology and Neurosurgery, McGill University, Montreal Neurological Institute, Montreal, \\ Quebec, H3A 2B4, Canada
}

Multiple lines of evidence indicate that neurons within the pontomesencephalic tegmentum are critically involved in the generation of paradoxical sleep (PS). From single-unit recording studies, evidence suggests that unidentified but "possibly" cholinergic tegmental neurons discharge at higher rates during PS than during slow wave sleep or even waking and would thus play an active role, whereas "presumed" monoaminergic neurons cease firing during PS and would thus play a permissive role in PS generation. In the present study performed on rats, c-Fos immunostaining was used as a reflection of neuronal activity and combined with immunostaining for choline acetyltransferase (ChAT), serotonin (Ser), tyrosine hydroxylase (TH), or glutamic acid decarboxylase (GAD) for immunohistochemical identification of active neurons during PS recovery $(\sim 28 \%$ of recording time) as compared with PS deprivation (0\%) and PS control $(\sim 15 \%)$ conditions. With PS recovery, there was a significant increase in ChAT $+/ c-F o s+$ cells, a significant decrease in Ser+/c-Fos + and $\mathrm{TH}+/ \mathrm{c}-\mathrm{Fos}+$ cells, and a significant increase in GAD+/c-Fos + cells. Across conditions, the percent PS was correlated positively with tegmental cholinergic c-Fos + cells, negatively with raphe serotonergic and locus coeruleus noradrenergic c-Fos + cells, and positively with codistributed and neighboring GABAergic c-Fos + cells. These results support the hypothesis that cholinergic neurons are active, whereas monoaminergic neurons are inactive during PS. They moreover indicate that GABAergic neurons are active during PS and could thus be responsible for inhibiting neighboring monoaminergic neurons that may be essential in the generation of PS.

Key words: paradoxical sleep; c-Fos expression; cholinergic; serotonergic; noradrenergic; GABAergic; sleep-wake states
Since early studies using transections and lesions, the pontomesencephalic tegmentum has been known to be critical for the generation of paradoxical sleep [(PS), or rapid eye movement (REM) sleep] (Jouvet, 1962, 1972). Pharmacological evidence had indicated that acetylcholine (ACh) was important for the appearance of PS (Domino et al., 1968), and injections of the cholinergic agonist carbachol into the pontomesencephalic tegmentum was shown to elicit a state similar to natural PS (George et al., 1964). ACh was also known to be important for wakefulness, and enhancing ACh levels with acetylcholinesterase (AChE) inhibitors elicited a waking state (Domino et al., 1968) unless monoamines were first depleted with reserpine, in which case, it elicited PS (Karczmar et al., 1970). These early pharmacological studies thus suggested that cholinergic systems, particularly within the pontomesencephalic tegmentum, were involved in the generation of PS but were also involved in waking and could only elicit PS when monoaminergic systems were inactivated.

After immunohistochemical localization of the cholinergic neurons in the pontomesencephalic tegmentum (Mesulam et al., 1983; Jones and Beaudet, 1987), it was demonstrated that neurotoxic lesions of these neurons resulted in the loss of PS (Jones and

\footnotetext{
Received Oct. 19, 1998; revised Jan. 22, 1999; accepted Feb. 1, 1999.

This research was supported by a grant to B.E.J. from the Medical Research Council of Canada. We would like to thank Melodee Mograss for her contribution to pilot studies.

Correspondence should be addressed to Dr. Barbara E. Jones, Montreal Neurological Institute, 3801 University Street, Montreal, Quebec H3A 2B4, Canada. Copyright (C) 1999 Society for Neuroscience $0270-6474 / 99 / 193057-16 \$ 05.00 / 0$
}

Webster, 1988; Webster and Jones, 1988; Jones, 1991b). Singleunit recording within the cholinergic cell area, including the laterodorsal and pedunculopontine tegmental nuclei, found cells that discharged at higher rates during PS than during slow wave sleep (SWS) and some that fired at even higher rates during PS than during waking (El Mansari et al., 1989; Steriade et al., 1990a; Kayama et al., 1992). In contrast, presumed serotonergic raphe neurons and presumed noradrenergic locus coeruleus neurons were found to fire at their lowest rates or cease firing altogether during PS (Hobson et al., 1975; McCarley and Hobson, 1975; McGinty and Harper, 1976). These electrophysiological results supported the hypothesis that PS is generated by an active involvement of cholinergic neurons, considered to be "PS-on" cells, and a permissive role of monoaminergic neurons, considered to be "PS-off" cells (McCarley and Hobson, 1975; Sakai, 1988; McCarley et al., 1995). The possibility was also raised that the cessation of firing by the monoaminergic neurons could be caused by active inhibition by local GABAergic neurons, which are distributed within these cell groups and neighboring areas (Jones, 1991a,b,c, 1993; Ford et al., 1995). The validation of these hypotheses depends, however, on the chemical identification of the recorded units, which has not yet been possible in naturally sleeping-waking animals.

Another method of studying neuronal activity, which permits immunohistochemical identification of the active cells, is by examination of c-Fos, the product of the immediate early gene that is expressed in association with neuronal discharge and entry of $\mathrm{Na}^{+}$and $\mathrm{Ca}^{2+}$ ions (Morgan and Curran, 1986; Dragunow and Faull, 1989). c-Fos expression combined with immunohistochem- 


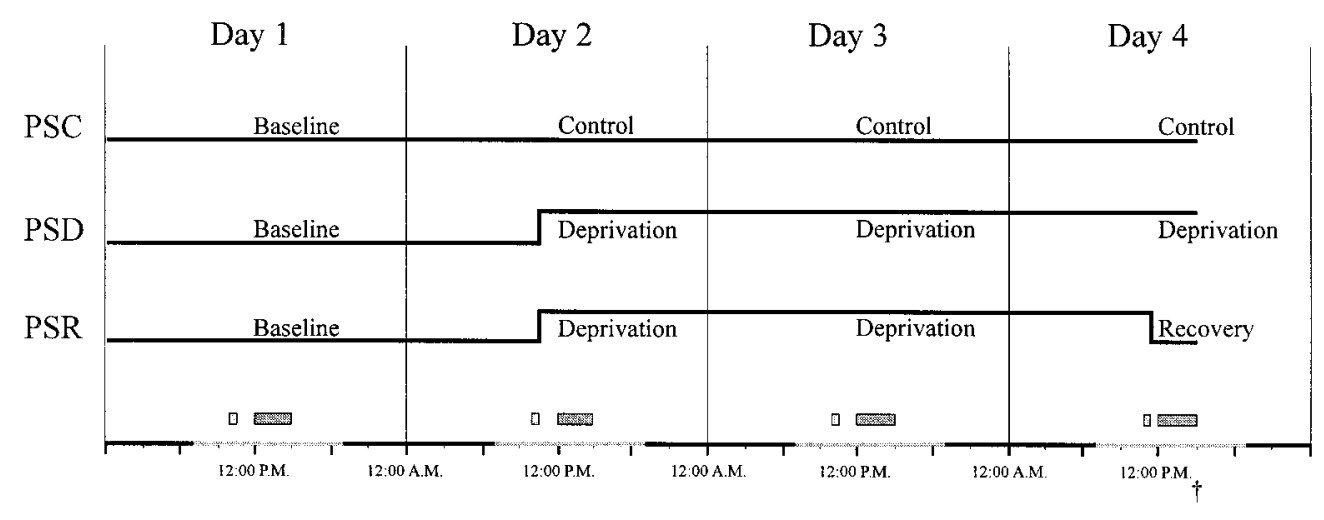

Figure 1. Diagram illustrating time course of treatments for the three different experimental conditions: PSC, PSD, and PSR. Whereas the PSC group remained on a bed of woodchips, the PSD and PSR groups were placed on inverted flower pots surrounded by water for $\sim 53$ or $\sim 50 \mathrm{hr}$ deprivation of PS (Days 2-4) in the recording chambers. The PSR group was returned to the woodchips to allow $\sim 3 \mathrm{hr}$ recovery of PS. Animals were anesthetized and perfused $(\dagger)$ at the end of the control, deprivation, or recovery periods (on day 4). EEG recording was performed each day for $3 \mathrm{hr}$ in the afternoon. Animals were maintained on a $12 \mathrm{hr}$ light/dark cycle (with lights on from 7:00 A.M. to 7:00 P.M., as indicated by light shading). See Materials and Methods for further details.

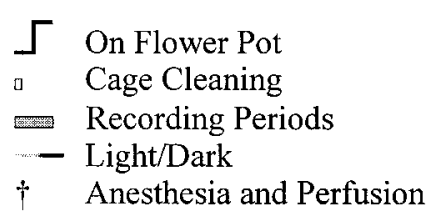

ical staining for cholinergic and monoaminergic neurons has been used in cats in the study of neurons active during carbacholinduced PS (Shiromani et al., 1992; Yamuy et al., 1995, 1998), yet this state may fundamentally differ from naturally generated PS. In the present study performed in rats, we sought to examine c-Fos expression in association with naturally enhanced PS during rebound from PS deprivation (Mendelson, 1974). Dual immunostaining for c-Fos protein and neurotransmitters or their enzymes was used for relative assessment of activity in cholinergic, serotonergic, noradrenergic, and GABAergic neurons in the pontomesencephalic tegmentum of animals under conditions of PS recovery, deprivation, and control (Maloney and Jones, 1997).

\section{MATERIALS AND METHODS}

Animals and surgery. Sixteen male Wistar rats (Charles River, Montreal, Quebec, Canada), weighing $\sim 225 \mathrm{gm}$, were operated under barbiturate anesthesia (Somnotol; $67 \mathrm{mg} / \mathrm{kg}$, i.p.) for the implantation of chronically indwelling electrodes. For the electroencephalogram (EEG), stainless steel screws were threaded into holes drilled in the skull so that the screws were in gentle contact with the dura. They were placed over the left and right retrosplenial, anterior frontal, parietal, and occipital cortices, as described previously (Maloney et al., 1997). One electrode was placed in the frontal bone rostral to the frontal lobes to be used as a reference for monopolar recording from each cortical lead and one in the occipital bone over the cerebellum to be used as a ground electrode. For the electromyogram (EMG), two stainless steel loops were inserted into the muscles of the neck. All leads were connected to a miniature (12 lead) plug that was cemented to the skull. Animals were allowed 2 or $3 \mathrm{~d}$ recovery from surgery in the animal room before being placed in recording chambers for the duration of the experiment.

Recording and experimental procedures. For recording and experimentation, each rat was placed in a Plexiglas box that was contained within a larger electrically shielded recording chamber. The rat was connected to a cable that was attached to a commutator and suspended with a balanced boom to allow free movement of the animal within the box. During the baseline day and in the control condition, the floor of the box was covered with woodchips. The animal had ad libitum access to food and water in containers that hung within easy reach on the sides of the box. As was the case in the animal room, a $12 \mathrm{hr}$ light/dark cycle was maintained in the recording room (with lights on from 7:00 A.M. to 7:00 P.M.). The rat was placed in the recording box and connected to the cable $3 \mathrm{~d}$ before baseline recording to allow for habituation to the recording environment.
The EEG and EMG signals were amplified using a Grass model 78D polygraph and subsequently sent to a computer (ALR 386SX) for analogto-digital conversion, filtering, and storage on hard disk with the aid of Stellate Systems (Montreal, Quebec, Canada) computer software, as described previously (Maloney et al., 1997).

PS deprivation was performed using the flower pot technique that has previously been shown to cause a fairly selective deprivation of PS in rats (Mendelson, 1974). It was also shown to not be associated with significant changes in adrenal gland weights (Mendelson, 1974), thus not producing a severe level of stress in the animals. Each rat was placed on an inverted flower pot that was just large enough $(\sim 6.5 \mathrm{~cm}$ in diameter) to hold the animal. The flower pot was surrounded by water that filled the Plexiglas box to within $1 \mathrm{~cm}$ of the surface of the inverted pot. In this situation, the animal could engage in SWS but not PS, because the loss of muscle tonus that occurs with PS onset causes the animal to fall into the water and awaken. Food and water containers were positioned to be easily accessible to the animal on the flower pot. Under these experimental conditions, it was determined in preliminary recording experiments (involving four rats operated for implantation of electrodes and tested in the recording and experimental paradigm) that after the first $24 \mathrm{hr}$ on the flower pots during which a certain degree of habituation to the experimental situation occurred, SWS appeared in ostensibly normal amounts but PS remained suppressed, producing a relatively selective deprivation of PS in the second $24 \mathrm{hr}$ deprivation period and selective rebound of PS after the deprivation. Accordingly, an $\sim 48 \mathrm{hr}$ deprivation period on the flower pots was selected for the experimental paradigm.

The experimental protocol was performed over a $4 \mathrm{~d}$ period in three groups of four rats (Fig. 1). Recordings were performed in the afternoon ( 12:00-3:00 P.M.) for the four consecutive days. On the first day, a baseline recording was performed on all animals. On the remaining $3 \mathrm{~d}$ of the experiment, the "condition" was varied for the three different groups: PS control (PSC), PS deprivation (PSD), and PS recovery (PSR). (1) For the control condition, the PSC animals remained on a bed of woodchips in their recording boxes for the $4 \mathrm{~d}$. During these days, they were left undisturbed, except in the morning ( 10:00-10:30 or $\sim 11: 00-$ 11:30 A.M.) when their boxes were cleaned, and food and water were replenished. At the termination of the experiment on day 4, the PSC animals were anesthetized for perfusion (at 3:00 or 3:30 P.M.) after the afternoon recording period (Fig. 1). (2) For the deprivation condition, the PSD animals were placed on flower pots for the second, third, and fourth days of the experiment. On these days, they were removed from their flower pots in the morning ( 10:00-10:30 or $\sim 11: 00-11: 30$ A.M.) while their boxes were being cleaned, and they were allowed to run around the larger dry recording chamber. On day 4 after the recording period, the PSD animals were anesthetized for perfusion (at $\sim 3: 30$ 
P.M.), having been in the deprivation condition for $\sim 53 \mathrm{hr}$ (Fig. 1). (3) For the recovery condition, the PSR animals were also placed on flower pots for the second, third, and fourth days like the PSD animals. Similarly, they were removed from their cages each morning ( 10:00-10:30 A.M.) while their boxes were cleaned. However, on day 4 after cage cleaning and after $\sim 50 \mathrm{hr}$ of PS deprivation, the animals were returned to a dry bed of woodchips in their recording boxes to allow for recovery of PS. To maximize the recovery during the final recording period $3 \mathrm{hr}$ before perfusion, the cage cleaning was performed at $\sim 11: 00$ A.M. on day 4 , and the animals were returned to the dry box at $\sim 11: 30$ A.M., thus allowing $\sim 30 \mathrm{~min}$ exploration and grooming before sleep onset and recording. All three groups of animals commonly tended to remain awake and active during the $\sim 30 \mathrm{~min}$ period after cage cleaning and handling (from 11:00-11:30 on day 4). After the recording period, the animals were anesthetized for perfusion (at $\sim 3: 00$ P.M.), having been in the PS recovery condition for $\sim 3 \mathrm{hr}$ after PS deprivation of $\sim 50 \mathrm{hr}$ (Fig. 1).

The experiments were conducted using two recording chambers and thus on two animals at one time, running pairs of PSD-PSR or PSC-PSC animals. Because the recovery condition was considered the most constrained with regard to time, the PSR animals were always anesthetized and perfused first at 3:00 P.M., whereas the paired PSD animals were anesthetized and perfused second at 3:30 P.M. For the PSC-PSC pairs, one PSC animal was anesthetized at $\sim 3: 00$ and the second at $\sim 3: 30$ P.M. The entire course of experiments involving six pairs of rats was conducted over a 3 month period during the winter season.

Pilot animals and procedures. Before the recording and experimental study described above, a pilot experiment was performed to test the effectiveness of the experimental paradigm and immunohistochemical revelation of c-Fos together with the neurotransmitters or enzymes. A series of twelve Wistar rats (Charles River), weighing $\sim 225 \mathrm{gm}$, were submitted to the three different experimental conditions described above, except that the pilot animals were not operated for implantation of electrodes and not attached to cables for recording. Another group of four rats were kept in the animal room, two to a cage in the manner that they are typically housed. These four groups of animals were anesthetized and perfused in pairs at $\sim 3: 00$ or $\sim 3: 30$ P.M. (as above).

Perfusion and fixation. The animals were killed under barbiturate anesthesia (Somnotol; $\sim 100 \mathrm{mg} / \mathrm{kg}$ ) by intraaortic perfusion of a fixative solution. The time between the barbiturate injection and initiation of the perfusion was $\sim 10 \mathrm{~min}$. One liter of $3 \%$ paraformaldehyde and $0.2 \%$ picric acid in $0.1 \mathrm{M}$ phosphate buffer was perfused for fixation and followed by $250 \mathrm{ml}$ of $10 \%$ sucrose in buffer. The brains were immersed in $30 \%$ sucrose overnight to complete cryoprotection. The brains were frozen at $-50^{\circ} \mathrm{C}$ and stored at $-80^{\circ} \mathrm{C}$.

Immunohistochemistry. Coronal sections were cut at $25 \mu \mathrm{m}$ thickness on a freezing microtome. Up to six series of adjacent sections were collected every $200 \mu \mathrm{m}$ for immunohistochemical processing. All immunohistochemistry was performed using the peroxidase-antiperoxidase (PAP) technique (Sternberger, 1979), according to previously published procedures (Gritti et al., 1993, 1997; Ford et al., 1995). For the immunostaining of c-Fos protein, an anti-c-Fos antiserum from sheep (Cambridge Research Biochemicals, Cheshire, UK) was used at a dilution of 1:3000. For immunostaining of neurotransmitters or their enzymes, the following antibodies were used: rabbit anti-choline-acetyl transferase (ChAT) antiserum (1:3000; Chemicon International, Temecula, CA), rabbit anti-serotonin (Ser) antiserum (1:30,000; Incstar, Stillwater, MN), rabbit anti-tyrosine hydroxylase (TH) antiserum (1:15,000; Eugene Tech International, Allendale, NJ), and rabbit anti-glutamic acid decarboxylase (GAD) antiserum (1:3000; Chemicon International). Incubations with primary antibodies were performed at room temperature overnight using a Tris-saline solution $(0.1 \mathrm{M})$ containing $1 \%$ normal donkey serum (NDS) and after incubation with Tris saline containing 6\% NDS for blocking. For antibodies to ChAT and TH, Triton X-100 (0.2\%) was added to the incubation solutions. Appropriate secondary antisera and PAP antibodies (Jackson ImmunoResearch Laboratories, West Grove, PA) were used after the respective primary antisera. In all brains, one series of sections was immunostained for c-Fos alone using the brown, floccular reaction product, 3,3' diaminobenzidine (DAB) as chromogen. In other adjacent series processed from the pilot and experimental brains, c-Fos was immunostained in combination with a neurotransmitter or enzyme using a sequential procedure staining c-Fos in either the first or second position. When in the first position, c-Fos was revealed with $\mathrm{DAB}$, and the neurotransmitter or enzyme was revealed with the blue granular reaction product, benzidine dihydrochloride (BDHC). In one set (PSD-PSR-PSC), c-Fos was revealed with DAB intensified with nickel $\left(\mathrm{DAB}-\mathrm{Ni}^{2+}\right)$ in the first position, and the neurotransmitter or enzyme revealed with DAB in the second position. In the major experimental series, the neurotransmitter or enzyme was immunostained and revealed in the first position with $\mathrm{DAB}$, and c-Fos was immunostained and revealed in the second position with BDHC. Controls in the absence of primary antibodies and in the presence of normal sera were routinely run with every single and dual immunostaining procedure to ensure the absence of nonspecific single or dual immunostaining in the material. Brains from sets of PSD-PSR, which were run together experimentally, were processed in the same manner for immunohistochemistry together with an accompanying PSC brain.

In assessing the effectiveness of the experimental paradigm and immunohistochemistry, qualitative examination of the material was performed by one of the experimenters (B.E.J.) who had knowledge of the experimental groups. In comparing the numbers of c-Fos immunostained cells across the different conditions used in the pilot and experimental studies, it was apparent that few to no cells were stained in brains from animals housed in pairs in the animal colony, many cells were stained in animals kept for $4 \mathrm{~d}$ under control conditions housed individually in the recording chambers, and many more cells were stained in animals that had been operated for implantation of electrodes and were attached to recording cables for $4 \mathrm{~d}$ under control conditions in the recording chambers. It was thus clear that the base level of c-Fos expression in the pilot and more so experimental animals was relatively high and could be attributed to the degree of stress associated with isolation, a new environment, surgery, and being tethered, despite allowing habituation to the recording environment and recovery from surgery. c-Fos expression has been known to be elevated in widespread areas in response to stress (Pezzone et al., 1993; Chen and Herbert, 1995; Cullinan et al., 1995). The level of c-Fos expression caused by these factors would however be the same for the three pilot and the three experimental groups, respectively, that were being compared among themselves. Qualitative differences in c-Fos immunostaining could be detected across the three different conditions of the pilot and experimental groups, respectively, and appeared systematic across these conditions in the two groups.

In the pilot series, c-Fos was immunostained in the first position, and the neurotransmitter or enzyme was immunostained in the second position. In this series, it was clear that more $\mathrm{TH}+$ cells in the locus coeruleus were c-Fos + in the PSD group than in the PSR group. However, it was difficult to clearly discern the ChAT and GAD immunostaining in the second position and thus to appreciate changes in the number of ChAT + and GAD + cells expressing c-Fos across the different groups. Thus, for the major experimental series, the immunostaining procedure was changed so that the neurotransmitter or enzyme was stained in the first position (with $\mathrm{DAB}$ ), and c-Fos was stained in the second position (with $\mathrm{BDHC}$ ). This procedure reduced the sensitivity of the c-Fos immunostaining particularly in the $\mathrm{TH}+$ cells and also in Ser + cells, in which the $\mathrm{TH}$ and serotonin staining was intense. However, it greatly enhanced the immunostaining, and thus identification of cells containing ChAT and GAD, in which ChAT and GAD staining was only moderate and c-Fos staining thus less affected. Because brains were processed in pairs from PSD-PSR animals and subsequently in a like manner from a matching PSC animal, it could be determined that the relative differences across groups were the same independent of the immunostaining procedure, although the absolute numbers of c-Fos-immunostained cells were lower with the c-Fos staining in the second position.

Analysis of sleep-wake state data. The EEG was examined by off-line analysis on computer screen and scored for sleep-wake state by visual assessment of EEG and EMG activity in $20 \mathrm{sec}$ epochs using Eclipse software (Stellate Systems) for each $3 \mathrm{hr}$ recording session ( $\sim 540 \mathrm{ep}-$ ochs). Epochs were scored as one of the three major states (Wake, SWS, or PS) or transitional $(t)$ stages between states: (1) wake marked by the presence of low-voltage fast activity associated with EMG tonus, (2) transition from wake into slow wave sleep ( $t$ SWS) characterized by moderate amplitude slow or mixed slow, spindle and fast activity, (3) slow wave sleep (SWS) marked by continuous high-amplitude slow activity, (4) transition from slow wave sleep into PS ( $t$ PS) marked by a decrease in high-amplitude slow activity and the appearance of spindles and theta waves, or (5) PS characterized by a prominence of theta waves, in addition to low-voltage fast activity, with low EMG activity.

The number of epochs scored in each state was calculated as a percent of total epochs in the $3 \mathrm{hr}$ recording session for each day. An overall statistic was performed using a repeated measures ANOVA with two trial factors ("state" and "day") and one grouping factor ("condition"). 
Data were further analyzed per state by repeated measures ANOVA tests with one trial factor (day) and one grouping factor (condition). When a main effect of condition was significant, post hoc tests were performed per day across groups (PSR or PSD vs PSC; PSR vs PSD) using Fisher's pairwise comparison. In the case in which there was a significant difference between groups (condition), another test was performed to determine whether there was also a significant difference between days 2, 3, or 4 and day 1 in that group. These tests were performed per state and condition, using a repeated measures ANOVA with one trial factor (day) and post hoc tests performed between the experimental days (day 2, 3, or 4) and baseline day (day 1). The number of PS episodes and the mean duration of these episodes were also calculated for the baseline day 1 and recovery day 4 of each animal in the PSR condition and analyzed by $t$ test paired comparisons.

Fast Fourier Transform was performed using Rhythm software (Stellate Systems) to determine power in EEG frequency bands for the $20 \mathrm{sec}$ state-scored epoch data, as described previously (Maloney et al., 1997). Frequency bands were set at the following ranges: delta, 1.5-4.0 Hz; theta, 4.5-8.5 Hz; and gamma, 30.5-58.0 Hz. The ratio of theta/delta, which reflects theta rhythmicity on the EEG, was also calculated and displayed. EMG amplitude was computed for the total spectrum up to 58.0 Hz. Changes in frequency band activities across experimental conditions were examined by statistical analysis of activities from the right retrosplenial lead. Frequency band activity was normalized for each rat according to the average amplitude values per state in the baseline day. Statistical differences in frequency band activity per state and condition were tested by repeated measures ANOVA with one trial factor (day).

Analysis of immunohistochemical data. Sections were viewed with a Leitz Orthoplan microscope equipped with an $\mathrm{x} / \mathrm{y}$ movement-sensitive stage and CCD camera attached to a computer. Single- and dualimmunostained cells were mapped using a computer-based image analysis system (Biocom, Paris, France) with a resident atlas of sections through the pontomesencephalic tegmentum (Jones, 1995). The experimenter (K.J.M.) mapping the cells did not have knowledge of the experimental group (PSD, PSR, PSC) to which the individual brains belonged. She was only given this information after all the data were tabulated on computer spreadsheets, and the group condition was inserted for the statistical analysis of the completed data set. Cell counts were tabulated automatically within each nucleus or region, including those of the cholinergic, serotonergic, and noradrenergic cell groups and the adjacent central gray areas of the pontomesencephalic tegmentum. Single c-Fos-immunostained cells were mapped and counted unilaterally (in one or two sections) at one or two representative of three stereotaxic levels corresponding approximately to anterior (A) 0.5, A 0.1, and posterior (P) 0.3, depending on the specific nucleus (Paxinos and Watson, 1986; Jones, 1995). To allow a more thorough sampling of dual immunostained cells, which were less numerous than the single c-Fosimmunostained cells and represented the focus of the present study, double-labeled cells were counted bilaterally at $200 \mu \mathrm{m}$ intervals through the full rostrocaudal extent of each cholinergic and serotonergic cell group and individual nucleus (in four to six sections between $\sim \mathrm{A} 1.1$ and $\sim \mathrm{P} 0.5$ depending on the specific nucleus) and through the rostral to midportion of the noradrenergic cell group (for two or three sections, between $\sim \mathrm{P} 0.1$ and $\sim \mathrm{P} 0.5$ depending on the specific nucleus). GAD $+/$ c-Fos + cells were counted on adjacent sections to $\mathrm{ChAT}+/ \mathrm{c}-\mathrm{Fos}+$, Ser $+/ \mathrm{c}-\mathrm{Fos}+$, or $\mathrm{TH}+/ \mathrm{c}-\mathrm{Fos}+$ cells in the same cell groups and nuclei, except the locus coeruleus (where too few GAD + cells are located, (Ford et al., 1995)) and additionally in the rostral and caudal central gray areas neighboring the dorsal raphe and locus coeruleus, respectively. The bilateral cell counts for dual-immunostained cells were averaged per section across the two sides. ANOVAs or ANCOVAs were performed on the cell counts across conditions in multiple sections per nucleus per cell group (cholinergic, serotonergic, noradrenergic, or central gray) per animal. Overall statistical differences in the number of cells caused by condition were examined in each cell group by one-way ANCOVA with condition as the grouping factor and nucleus, section, and animal as covariates. Statistical differences in the number of cells in individual nuclei within each cell group were subsequently examined using a oneway ANCOVA with condition as grouping factor and section and animal as covariates. When there was a significant main effect, differences in cell counts between individual conditions were analyzed by post hoc analyses using Fisher's pairwise comparisons (with significance level set at $p \leq$ $0.05)$. For tabular presentation and regression analysis, the total number of labeled cells was calculated for each nucleus and cell group by adding (absolute or averaged) unilateral counts across sections in individual animals. Correlations between total number of labeled cells counted per nucleus or cell group and the percent PS, SWS, or wake were performed by multiple linear regression analyses with animal as a covariate. All statistics were performed using Systat for Windows (Evanston, Illinois). Figures were prepared for publication using CorelDraw (Ottawa, Ontario).

\section{RESULTS}

\section{Sleep-wake states}

The PS deprivation procedure, which commenced on day 2 of the experimental paradigm for animals of the deprivation and recovery conditions (Fig. 1), was effective in producing a near complete elimination of PS, as well as a significant decrease in the transitional state into PS ( $t$ PS), as measured during $3 \mathrm{hr}$ recording periods on days 2 and 3 in the deprivation and recovery conditions (Table 1, PSD, PSR). The decrease in PS and $t$ PS was associated with a significant increase in waking. Although SWS was reduced, particularly on the first deprivation day, it was not significantly less than that in the PSC group during the deprivation days (Table 1).

In comparing the sleep-wake states across the different conditions on day 4 when the recovery group was removed from the deprivation condition (Fig. 1), it was apparent that there was a relatively selective deprivation of PS in the deprivation condition (PSD) and a relatively selective recovery of PS in the recovery condition (PSR), as compared with the control condition (PSC) in the final $3 \mathrm{hr}$ before anesthesia and perfusion (Table 1). Thus, after $\sim 53$ and $50 \mathrm{hr}$ of deprivation, respectively, PS represented $0 \%$ in the deprivation condition and $\sim 28 \%$ in the recovery condition, as compared with $\sim 15 \%$ in the control condition. SWS was less in the deprivation condition than in control, but not significantly so; wake was significantly greater in the deprivation condition (Table 1). SWS was significantly greater in the recovery condition than in control or deprivation, however it was not significantly different from baseline within the same group (Table 1 , as indicated by parentheses). As compared with both control and baseline conditions, therefore, PS was the one state that was commonly altered in the two experimental conditions, being significantly decreased in the deprivation and significantly increased in the recovery condition.

Although the experimental procedure was effective in producing a relatively selective deprivation and recovery of PS, it did so without causing major changes in the EEG characteristics of the extant states of wake and SWS during deprivation, as well as of PS during recovery (Fig. 2). According to visual inspection of the record and quantitative assessment of frequency band activity, the EEG was relatively unchanged during waking and was characterized, as in baseline and control conditions, by highfrequency gamma activity and theta waves recorded from limbic cortex [Figs. 2, right retrosplenial $(R R S), 3,4]$. Across deprivation days, though, there was a progressive increase in gamma activity during waking that was significant for the deprivation condition $(F=6.068 ;$ df $=3 ; p<0.05)$. The EEG during SWS was relatively unaltered and characterized as in baseline and control conditions by high-amplitude delta waves during deprivation and recovery (Figs. 2-4). There were no significant differences in amplitude of delta activity in SWS. PS during recovery (day 4) appeared similar in its EEG characteristics to that during baseline (Figs. 2, 4, Day 1). Gamma and theta activities were not quantitatively different from those in baseline PS. The change in PS during recovery was thus measured as being only in amount (Fig. 4 ), which particularly reflected consistently increased duration of 
Table 1. Sleep-wake states across days for PSC, PSD, and PSR groups

\begin{tabular}{lcccc}
\multicolumn{1}{c}{ Day 1} & Day 2 & Day 3 & Day 4 \\
\hline PSC & & & \\
WAKE & $21.82 \pm 5.10$ & $19.05 \pm 5.46$ & $13.85 \pm 4.09$ & $21.00 \pm 2.00$ \\
$t$ SWS & $27.34 \pm 1.43$ & $28.75 \pm 4.40$ & $32.00 \pm 1.00$ & $30.00 \pm 5.00$ \\
SWS & $11.50 \pm 3.14$ & $15.72 \pm 6.39$ & $10.39 \pm 4.38$ & $9.00 \pm 3.00$ \\
$t$ PS & $25.75 \pm 4.21$ & $23.75 \pm 4.13$ & $28.67 \pm 1.67$ & $25.00 \pm 4.00$ \\
$\quad$ PS & $11.61 \pm 2.31$ & $12.73 \pm 1.13$ & $10.37 \pm 3.95$ & $14.50 \pm 6.50$ \\
PSD & & & & \\
WAKE & $21.65 \pm 3.59$ & $72.89 \pm 3.18^{*}$ & $52.89 \pm 7.75\left(^{*}\right)$ & $56.32 \pm 3.87^{*}$ \\
$t$ SWS & $36.92 \pm 7.02$ & $22.05 \pm 3.49$ & $33.75 \pm 6.28$ & $34.00 \pm 4.74$ \\
SWS & $8.65 \pm 2.46$ & $2.25 \pm 0.59$ & $5.96 \pm 1.19$ & $3.04 \pm 1.53$ \\
$t$ PS & $23.54 \pm 5.01$ & $0.50 \pm 0.29^{*}$ & $7.25 \pm 2.18\left(^{*}\right)$ & $6.25 \pm 1.03\left(^{*}\right)$ \\
PS & $12.43 \pm 4.57$ & $0.0 \pm 0.0^{*}$ & $0.3 \pm 0.5^{*}$ & $0.0 \pm 0.0^{*}$ \\
PSR & & & & \\
WAKE & $20.89 \pm 2.88$ & $76.35 \pm 2.37^{*}$ & $49.90 \pm 3.23^{*}$ & $16.36 \pm 1.28(\dagger)$ \\
$t$ SWS & $21.88 \pm 3.83$ & $20.07 \pm 2.59$ & $25.18 \pm 0.84$ & $10.75 \pm 2.60$ \\
SWS & $25.64 \pm 1.67^{*}, \dagger$ & $2.95 \pm 0.61$ & $13.58 \pm 1.50 \dagger$ & $25.51 \pm 1.06\left(^{*}, \dagger\right)$ \\
$t$ PS & $18.25 \pm 4.42$ & $0.0 \pm 0.0^{*}$ & $10.36 \pm 3.21^{*}$ & $19.25 \pm 1.32\left(^{*}, \dagger\right)$ \\
PS & $12.83 \pm 1.23$ & $0.0 \pm 0.0^{*}$ & $0.0 \pm 0.0^{*}$ & $28.37 \pm 1.86^{*}, \dagger$
\end{tabular}

Percentage of time spent in Wake, $t$ SWS (transition from Wake to SWS), SWS, $t$ PS (transition from SWS to PS), and PS per day (scored per 20 sec epoch over $\sim 3$ hour recording period) across the four experimental days for animals in each condition (mean $\pm \mathrm{SEM}, n=4)$. A repeated measures ANOVA was performed on the entire data set with two trial factors ("state" and "day") and one grouping factor ("condition") and revealed significant variance across state with a significant interaction of state with condition, day, and condition and day. The data were further analyzed per state by repeated measures ANOVA tests with one trial factor (day) and one grouping factor (condition). There was a significant main effect of condition for W, SWS, $t$ PS, and PS. In these cases, post hoc tests were performed per day across conditions (PSR or PSD vs PSC; PSR vs PSD) using Fisher's pairwise comparisons. In cases where there was a significant difference between conditions on days 2, 3, or 4, another post hoc test was performed to determine whether there was a significant difference between those experimental days and day 1 (baseline) within that group.

Differences with respect to PSC are indicated by $* x \leq 0.05$.

Differences in PSR with respect to PSD are indicated by $\dagger p \leq 0.05$.

In those cases in which there was not a significant difference with respect to baseline, the symbols are placed within parentheses.

PSD
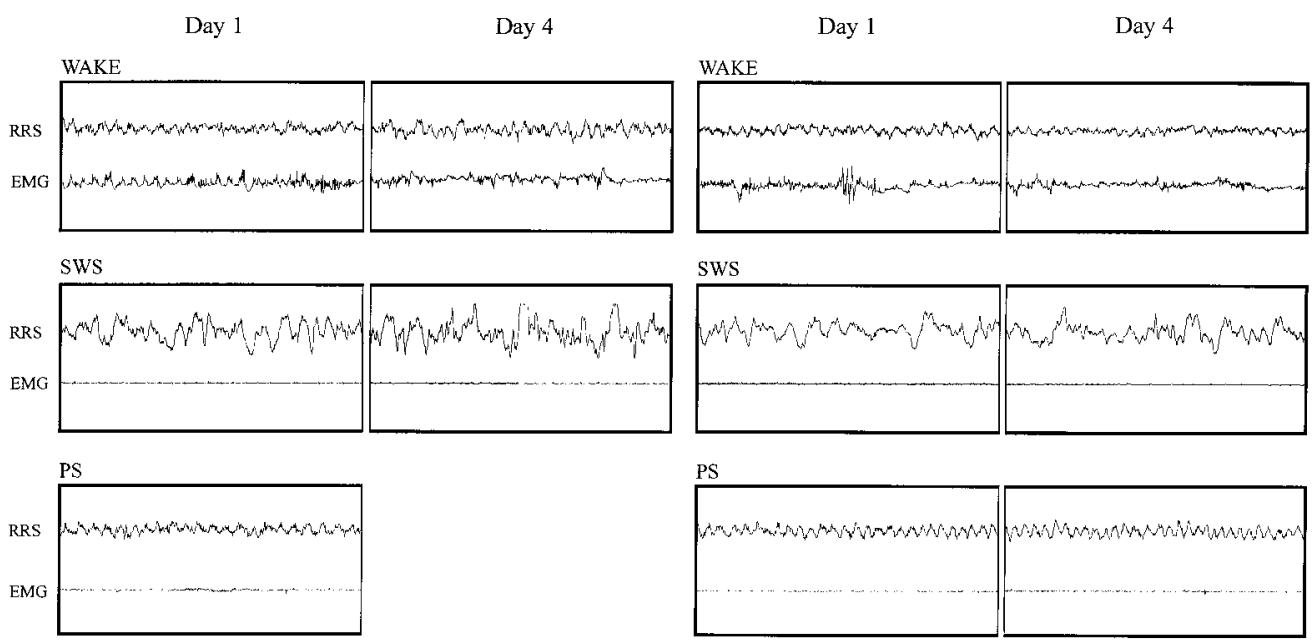

$\overline{1 \sec }$
Figure 2. EEG and EMG associated with wake, SWS, and PS on day 1 (baseline) and day 4 from two representative animals within the PSD (left) and PSR (right) groups. There is no apparent difference in EEG activity during wake or SWS in either group or during PS in the recovery group between days 1 and 4 . The EEG was recorded from the RRS cortex.
PS episodes $(2.44 \pm 0.49$ vs $1.84 \pm 0.35 \mathrm{~min}$, mean $\pm \mathrm{SEM} ; t=$ 12.5; df $=3 ; p<0.05$ with paired comparison of recovery to baseline values), in addition to frequently increased numbers of PS episodes $(23 \pm 4.3$ vs $17 \pm 2.7 ; t=1.58$; df $=3$, not significant).

\section{c-Fos+ expression in cell groups of the pontomesencephalic tegmentum}

The number of single-labeled c-Fos + cells varied significantly as a function of the experimental condition in most cell groups (Table 2, c-Fos + ). However, whether there was an increase or 
W
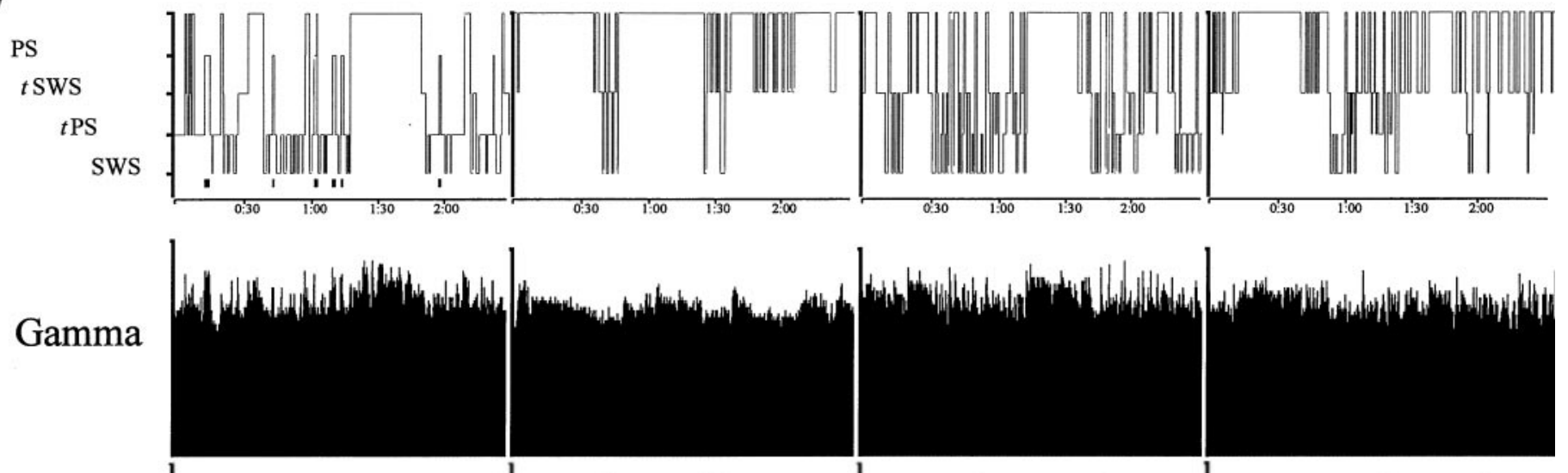

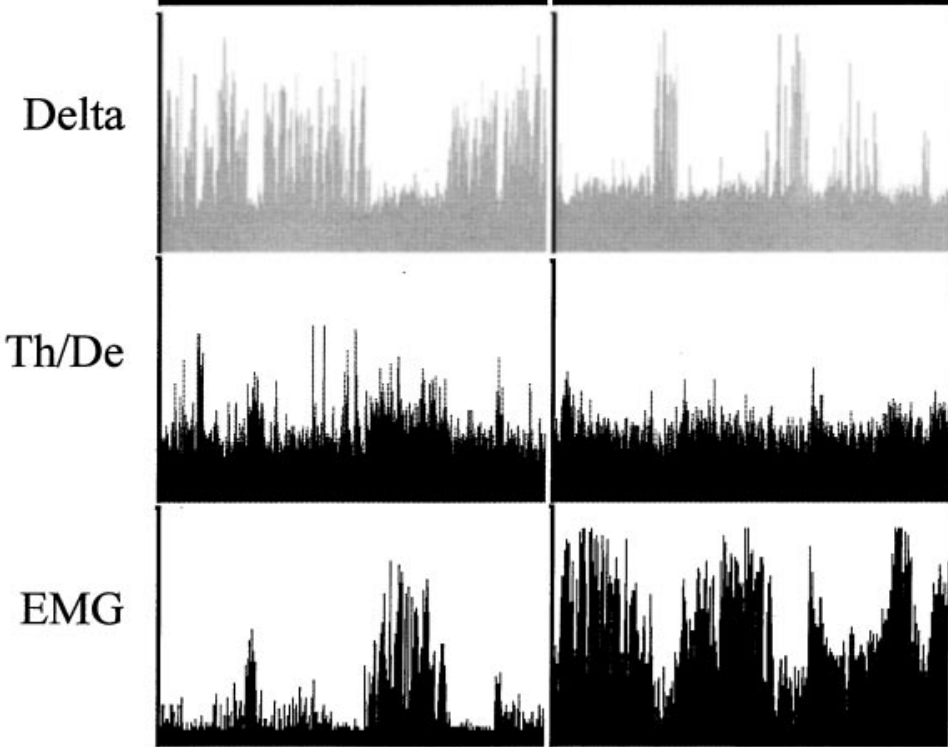

Day 1

(Baseline)
Day 2

(PS Deprivation)

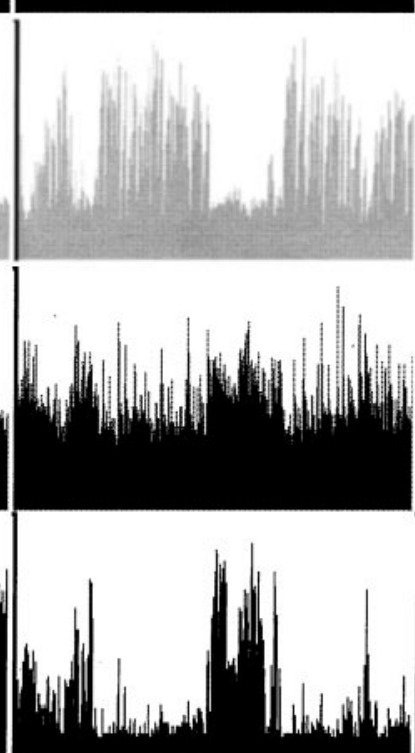

Day 3

(PS Deprivation)

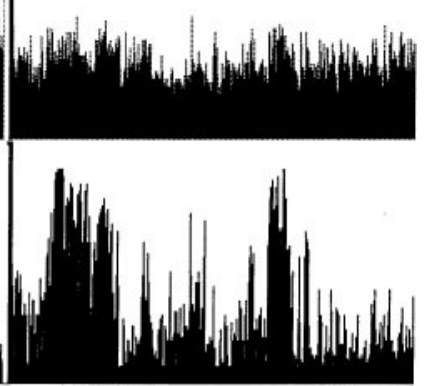

Day 4

(PS Deprivation)

Figure 3. Hypnogram showing sleep-wake states (top row, with PS also indicated by black bars underneath; scored per 20 sec epoch during the 3 hr recording period) over the four experimental days in one representative animal of the PSD condition. Activity in the gamma (30.5-58.0 $\mathrm{Hz})$ and delta $(1.5-4.0 \mathrm{~Hz})$ frequency bands and the ratio of theta $(4.5-8.5 \mathrm{~Hz})$ to delta $(T h / D e$, indicative of theta activity) are shown for EEG. Total activity $(1.5-58$ $\mathrm{Hz}$ ) is shown for EMG. Parallel increases in gamma and theta reflect cortical activation during wake and PS, which is also accompanied by low EMG activity, whereas high delta activity reflects SWS. Note on days 2, 3, and 4, the persistence of SWS marked by high-amplitude delta, despite the deprivation of PS. Activity displayed as amplitude units scaled to maximum.

decrease in the PS recovery condition depended on the individual cell group. In the cholinergic cell group, including its four nuclear subdivisions, c-Fos + cells were greater in the PSR condition than in the PSD or PSC conditions (Table 2, Sum). In the serotonergic cell group, including its two nuclear subdivisions, c-Fos + cells were not consistently different in the recovery condition. In the noradrenergic cell group, including its two nuclear subdivisions, c-Fos + cells were lower in the recovery condition than in the deprivation condition. In the central gray areas, which lie adjacent to the cholinergic and monoaminergic cell groups, c-Fos + cells were greater in the PS recovery condition than in the deprivation and control conditions. The different variations according to condition in c-Fos + cells across the different cell groups appeared to depend on the predominant cell types located in those regions, as could only be fully appreciated by dual immunostaining for c-Fos and specific neurotransmitter or synthetic enzyme (Figs. 5-8).

In the cholinergic cell group, ChAT-immunostained cells expressing c-Fos (Fig. 5A) varied significantly as a function of condition (Table 2, ChAT $+/ \mathrm{c}-\mathrm{Fos}+$ ). The sum of $\mathrm{ChAT}+/ \mathrm{c}-$ Fos + cells was greater in the recovery condition than in the deprivation and control conditions (Table 2, Sum). The greater number of $\mathrm{ChAT}+/ \mathrm{c}-\mathrm{Fos}+$ cells in the recovery condition as compared with the deprivation condition was apparent across the cholinergic nuclei of the pontomesencephalic tegmentum (Fig. 6, LDTg, LDTgV, PPTgM, PPTgL). Within individual nuclei, these differences were statistically significant for the laterodorsal tegmental nucleus (LDTg), in which the number of ChAT $+/ \mathrm{c}-\mathrm{Fos}+$ cells in the recovery condition was higher than in the deprivation condition, and for the pedunculopontine tegmental nucleus, medial part (PPTgM), in which the number of ChAT $+/ \mathrm{c}-\mathrm{Fos}+$ cells in the recovery condition was higher than in both the deprivation and control conditions (Table 2). Within the LDTg, the number of cells in the deprivation condition was also significantly lower than in the control condition. Across conditions, the number of ChAT $+/$ c-Fos + cells within the LDTg was significantly positively correlated with the percent time spent in PS during the final $3 \mathrm{hr}$ 
W
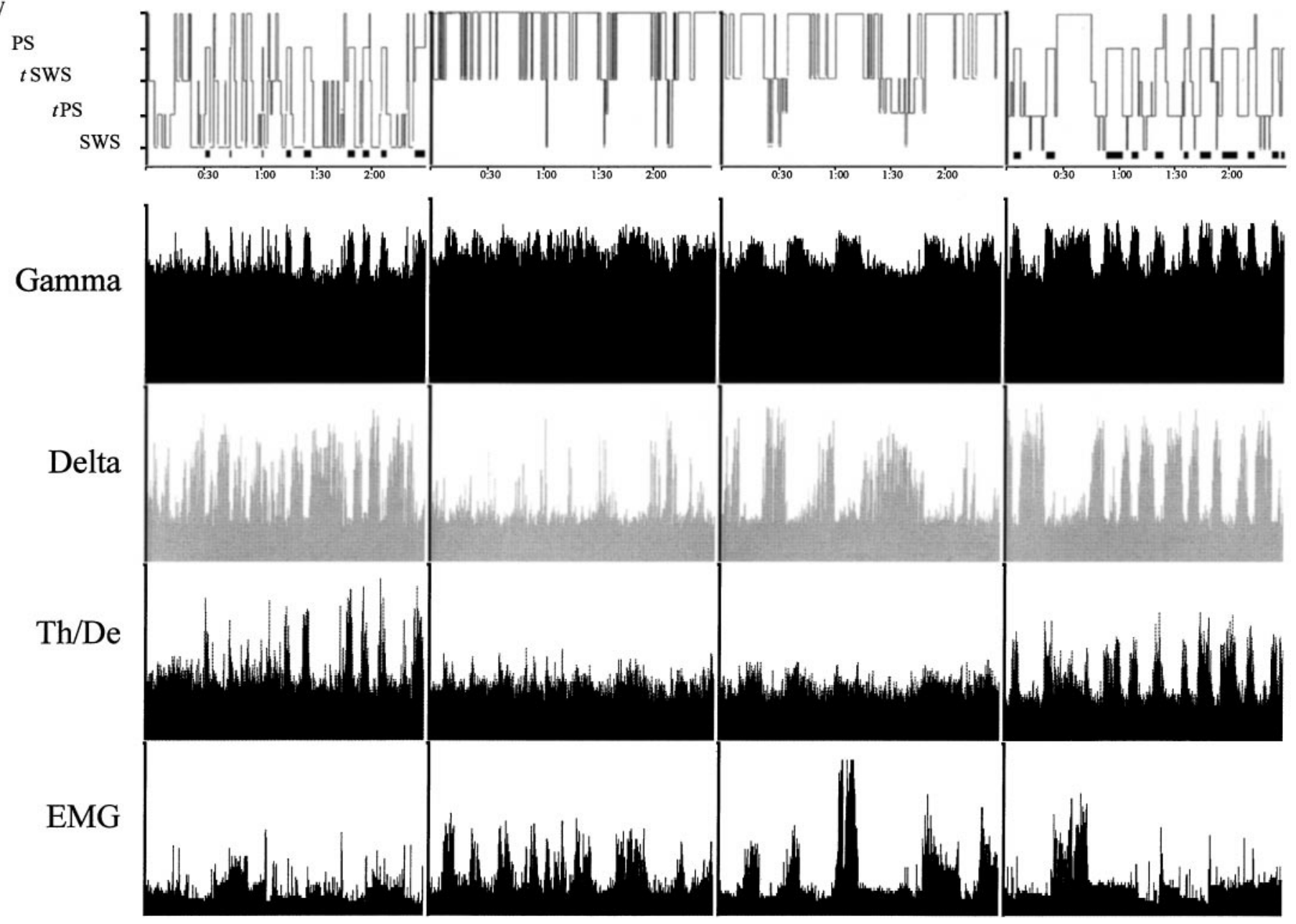

Day 1

Day 2

(Baseline)

(PS Deprivation)

Day 3

(PS Deprivation)
Day 4

(Recovery)

Figure 4. Hypnogram showing sleep-wake states (top row, with PS also indicated by black bars underneath; scored per 20 sec epoch during the 3 hr recording period) over the four experimental days in one representative animal of the PSR condition. Activity in the gamma (30.5-58.0 $\mathrm{Hz})$ and delta $(1.5-4.0 \mathrm{~Hz})$ frequency bands and the ratio of theta $(4.5-8.5 \mathrm{~Hz})$ over delta $(T h / D e$, indicative of theta activity) are shown for EEG. Total activity $(1.5-58$ $\mathrm{Hz}$ ) is shown for EMG. Parallel increases in gamma and theta reflect cortical activation during wake and PS, which is also accompanied by low EMG activity, whereas high delta activity reflects SWS. Note on days 2 and 3, the persistence of SWS marked by high-amplitude delta, despite the deprivation of PS. The recovery and rebound of PS is evident on day 4 by the presence of high-amplitude gamma and theta activity with diminished EMG. Activity displayed as amplitude units scaled to maximum.

recording period ( $r=0.68$; Fig. 9). It was not significantly correlated with the percent SWS but was significantly negatively correlated with the percent waking $(r=-0.73$; df $=11 ; p<.05)$. With stepwise backward removal of variables in a multiple regression linear model, removal of the waking variable did not eliminate the significant correlation of PS with the number of $\mathrm{ChAT}+/ \mathrm{c}-\mathrm{Fos}+$ cells.

In the serotonergic cell group, Ser-immunostained cells expressing c-Fos (Fig. 5C) varied significantly as a function of condition (Table 2, Ser+/c-Fos + ). The number of Ser $+/ \mathrm{c}-\mathrm{Fos}+$ cells was significantly lower in the recovery condition than in the deprivation and control conditions (Table 2, Sum). The lower number of Ser $+/ \mathrm{c}-\mathrm{Fos}+$ cells in the recovery condition as compared with the deprivation condition was apparent in both the dorsal and median raphe nuclei (Fig. 7, DR, MR). Within both nuclei, the difference between the recovery condition and deprivation and control conditions was significant (Table 2). Across conditions, the number of Ser $+/ \mathrm{c}-$ Fos + cells within the DR was significantly negatively correlated with the percent time spent in PS during the final $3 \mathrm{hr}$ recording period (Fig. 9; $r=-0.73$ ). It was not significantly correlated with either the percent SWS or waking.

In the noradrenergic cell group, TH-immunostained cells expressing c-Fos (Fig. 5D) varied significantly as a function of condition (Table 2, $\mathrm{TH}+/ \mathrm{c}-\mathrm{Fos}+$ ). The number of $\mathrm{TH}+/ \mathrm{c}-\mathrm{Fos}+$ cells was significantly lower in the recovery condition than in the deprivation condition (Table 2, Sum). The lower number of $\mathrm{TH}+/ \mathrm{c}-\mathrm{Fos}+$ cells in the recovery condition as compared with the deprivation condition was apparent in both the locus coeruleus and subcoeruleus, $\alpha$ part (Fig. 8, $L C, S u b C A$ ). Within both nuclei, the difference between the recovery condition and deprivation condition was significant (Table 2). In addition, for both the sum and $\mathrm{LC}, \mathrm{TH}+/ \mathrm{c}-\mathrm{Fos}+$ cells were significantly greater in the deprivation condition than in the control condition (Table 2, Sum 
Table 2. Number of identified single-labelled, c-Fos + neurons, or double-labelled, ChAT+/c-Fos + , Ser $+/ \mathrm{c}-\mathrm{Fos}+$, TH+/c-Fos + , and GAD+/c-Fos + neurons in the cholinergic, serotonergic, noradrenergic and adjacent central gray cell groups of the pontomesencephalic tegmentum in PSC, PSD, and PSR groups

\begin{tabular}{|c|c|c|c|c|c|c|c|c|}
\hline \multirow[b]{2}{*}{ Nucleus } & \multicolumn{4}{|l|}{ c-Fos $+^{a}$} & \multicolumn{4}{|l|}{$\mathrm{ChAT}+/ \mathrm{c}-\mathrm{Fos}+{ }^{b}$} \\
\hline & PSC & PSD & PSR & $\mathrm{F}$ & PSC & PSD & PSR & $\mathrm{F}$ \\
\hline LDTg & $61.25 \pm 10.08$ & $63.25 \pm 12.94$ & $106.38 \pm 14.89^{*}, \dagger$ & $\ddagger$ & $42.13 \pm 3.53$ & $23.33 \pm 5.93^{*}$ & $53.83 \pm 6.57 \dagger$ & $\ddagger$ \\
\hline $\mathrm{LDTgV}$ & $33.75 \pm 5.48$ & $53.13 \pm 5.23$ & $67.75 \pm 6.42^{*}$ & $\neq$ & $20.88 \pm 3.19$ & $15.00 \pm 1.53$ & $16.50 \pm 1.80$ & \\
\hline PPTgM & $113.25 \pm 34.79$ & $83.50 \pm 7.63$ & $96.25 \pm 7.64$ & & $12.75 \pm 3.43$ & $9.83 \pm 0.44$ & $20.83 \pm 4.34^{*}, \dagger$ & $\ddagger$ \\
\hline PPTgL & $177.50 \pm 57.47$ & $153.00 \pm 18.06$ & $257.50 \pm 77.33$ & & $24.63 \pm 4.71$ & $27.17 \pm 4.92$ & $32.00 \pm 1.00$ & \\
\hline $\operatorname{Sum}^{c}$ & $385.63 \pm 89.83$ & $352.88 \pm 22.38$ & $527.88 \pm 102.62^{*}, \dagger$ & $\neq$ & $100.25 \pm 12.83$ & $75.35 \pm 11.32$ & $123.17 \pm 12.41^{*}, \dagger$ & $\ddagger$ \\
\hline DR & $37.50 \pm 3.75$ & $64.50 \pm 28.12$ & $113.63 \pm 40.11^{*}, \dagger$ & $\ddagger$ & & & & \\
\hline MR & $267.75 \pm 109.45$ & $213.33 \pm 43.91$ & $109.33 \pm 32.09$ & & & & & \\
\hline $\operatorname{Sum}^{c}$ & $305.25 \pm 109.54$ & $224.50 \pm 44.37$ & $225.00 \pm 25.51$ & & & & & \\
\hline $\mathrm{LC}$ & $28.24 \pm 4.50$ & $32.75 \pm 3.43$ & $15.00 \pm 2.38^{*}, \dagger$ & $\ddagger$ & & & & \\
\hline SubCA & $63.00 \pm 12.99$ & $97.50 \pm 15.60$ & $61.00 \pm 13.37$ & & & & & \\
\hline $\operatorname{Sum}^{c}$ & $91.25 \pm 16.67$ & $130.25 \pm 17.19$ & $76.00 \pm 14.01 \dagger$ & $\ddagger$ & & & & \\
\hline rCG & $159.00 \pm 43.54$ & $142.75 \pm 11.81$ & $238.00 \pm 30.05^{*}, \dagger$ & $\ddagger$ & & & & \\
\hline cCG & $124.00 \pm 27.58$ & $120.25 \pm 16.47$ & $161.00 \pm 19.79$ & & & & & \\
\hline $\operatorname{Sum}^{c}$ & $283.00 \pm 63.02$ & $263.00 \pm 27.57$ & $399.00 \pm 48.96^{*}, \dagger$ & $\ddagger$ & & & & \\
\hline
\end{tabular}

Cell counts were taken from five adjacent series of sections cut at $25 \mu \mathrm{m}$ and collected at $200 \mu \mathrm{m}$ intervals.

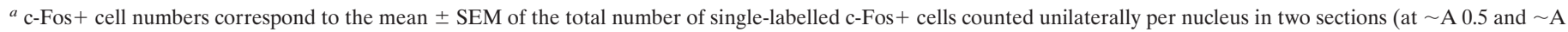

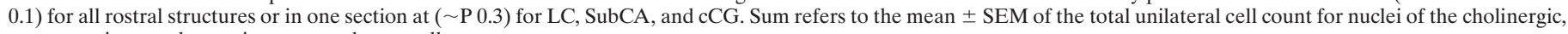
serotonergic, noradrenergic, or central gray cell groups.

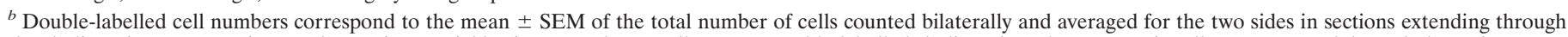

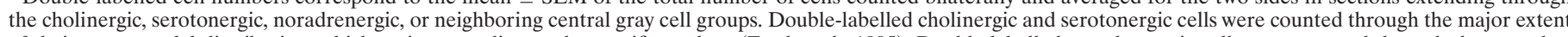

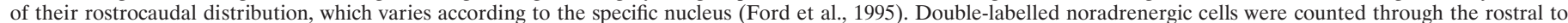

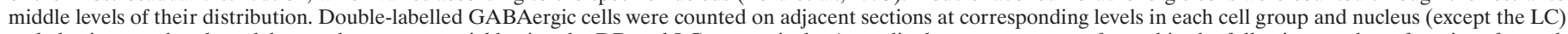

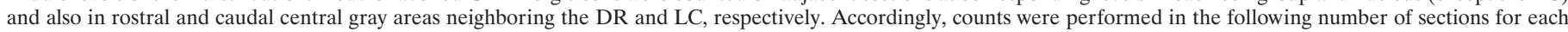

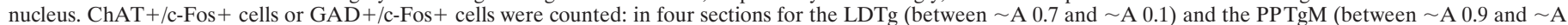

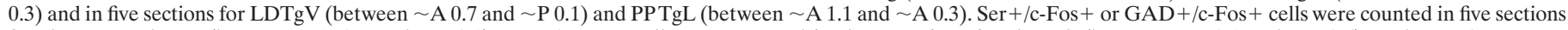

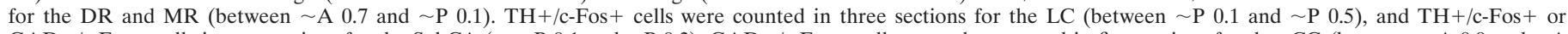

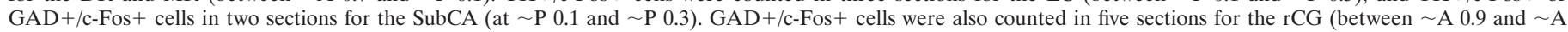

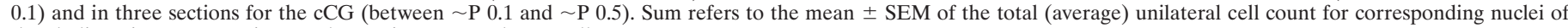
the cholinergic, serotonergic, noradrenergic, or central gray cell groups.

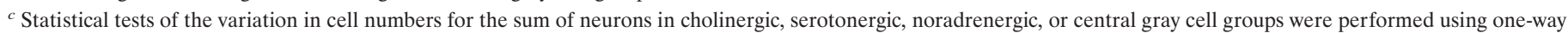
ANCOVAs with condition as grouping factor and nucleus, section, and animal as covariates.

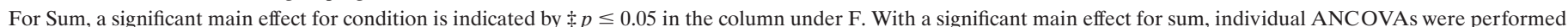

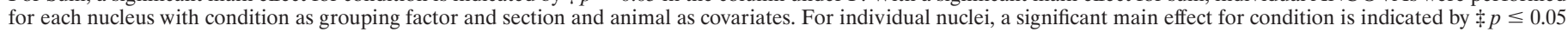

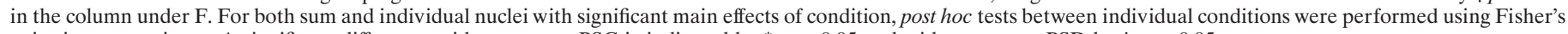
pairwise comparisons. A significant difference with respect to PSC is indicated by ${ }^{*} p \leq 0.05$ and with respect to PSD by $\uparrow \leq \leq 0.05$.

and LC). Across conditions, the number of $\mathrm{TH}+/ \mathrm{c}-\mathrm{Fos}+$ cells within the LC was significantly negatively correlated with the percent time spent in PS during the final $3 \mathrm{hr}$ recording period (Fig. 9; $r=-0.61$ ). It was not significantly correlated with the percent SWS but was significantly positively correlated with the percent waking $(r=0.60$; df $=11 ; p<0.05)$. With stepwise backward removal of variables in a multiple regression linear model, removal of the waking variable did not eliminate the significant correlation of PS with the number of $\mathrm{TH}+/ \mathrm{c}-\mathrm{Fos}+$ cells.

In all cell groups, including the central gray areas adjacent to the cholinergic and monoaminergic cell groups, GADimmunostained cells expressing c-Fos were evident (Fig. 5B) and varied significantly as a function of condition (Table 2, GAD+/ c-Fos + ). The number of GAD $+/ \mathrm{c}-$ Fos + cells was significantly higher in the recovery condition than in the deprivation and control conditions in all regions (Table 2, Sum). The higher number of $\mathrm{GAD}+/ \mathrm{c}-\mathrm{Fos}+$ cells in the recovery condition as compared with the deprivation condition was apparent in all cell groups and nuclei of the pontomesencephalic tegmentum where GAD + cells are distributed (Figs. 6-8). In every one of these nuclei, the number of GAD+/c-Fos + cells was consistently higher in the recovery condition than in the deprivation and control conditions (Table 2). In none of the groups or nuclei were there significant differences between the deprivation and control conditions (Table 2). Across conditions, the number of GAD+/ c-Fos + cells was significantly positively correlated with the percent time spent in PS in all nuclei, as illustrated for the cells in the LDTg $(r=0.85)$, the DR $(r=0.92)$, and the caudal central gray adjacent to the LC (Fig. 9; $r=0.70$ ). It was not significantly correlated with either the percent SWS or waking.

\section{DISCUSSION}

The present results demonstrate that during PS rebound, the number of c-Fos-expressing cholinergic cells is increased, whereas the numbers of c-Fos-expressing monoaminergic neurons are decreased, suggesting a reciprocal change in the activity of these cell groups. Moreover, the number of GABAergic cells expressing c-Fos during rebound is increased, suggesting that they may also be active during PS and involved in suppressing the activity of surrounding monoaminergic cells.

The changes in c-Fos expression are interpreted here as reflecting changes in neuronal activity associated with the different experimental conditions. It must be mentioned, nonetheless, that such changes may also reflect changes in other cellular processes that can be stimulated by chemical messengers independent of neuronal discharge, although also dependent on changes in intracellular calcium (Morgan and Curran, 1986). 


\begin{tabular}{|c|c|c|c|c|c|c|c|c|c|c|c|}
\hline \multicolumn{4}{|l|}{ Ser $+/ \mathrm{c}-\mathrm{Fos}+^{b}$} & \multicolumn{4}{|l|}{$\mathrm{TH}+/ \mathrm{c}-\mathrm{Fos}+{ }^{b}$} & \multicolumn{4}{|c|}{$\mathrm{GAD}+/ \mathrm{c}-\mathrm{Fos}+{ }^{b}$} \\
\hline PSC & PSD & PSR & $\mathrm{F}$ & PSC & PSD & PSR & $\mathrm{F}$ & PSC & PSD & PSR & $\mathrm{F}$ \\
\hline & & & & & & & & $29.50 \pm 10.77$ & $21.00 \pm 2.78$ & $87.33 \pm 13.37^{*}, \dagger$ & $\ddagger$ \\
\hline & & & & & & & & $11.67 \pm 2.96$ & $18.17 \pm 5.29$ & $31.00 \pm 6.76^{*}, \dagger$ & $\ddagger$ \\
\hline & & & & & & & & $26.17 \pm 11.61$ & $19.33 \pm 2.59$ & $44.40 \pm 9.68^{*}, \dagger$ & 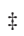 \\
\hline & & & & & & & & $29.17 \pm 2.32$ & $30.00 \pm 2.65$ & $57.33 \pm 21.36^{*}, \dagger$ & $\ddagger$ \\
\hline & & & & & & & & $96.33 \pm 17.46$ & $88.50 \pm 4.36$ & $220.07 \pm 46.25^{*}, \dagger$ & \# \\
\hline $24.87 \pm 3.60$ & $29.17 \pm 5.96$ & $12.83 \pm 0.88^{*}, \dagger$ & $\ddagger$ & & & & & $10.50 \pm 2.75$ & $7.67 \pm 2.60$ & $29.17 \pm 4.34^{*}, \dagger$ & $\ddagger$ \\
\hline $33.75 \pm 7.62$ & $39.75 \pm 11.25$ & $14.17 \pm 6.93^{*}, \dagger$ & $\ddagger$ & & & & & $44.67 \pm 14.17$ & $38.00 \pm 10.61$ & $104.83 \pm 35.55^{*}, \dagger$ & $\ddagger$ \\
\hline \multirow[t]{7}{*}{$58.50 \pm 11.26$} & $67.17 \pm 8.59$ & $27.00 \pm 7.29^{*}, \dagger$ & $\ddagger$ & & & & & $53.50 \pm 12.86$ & $45.67 \pm 8.82$ & $134.00 \pm 31.27^{*}, \dagger$ & $\ddagger$ \\
\hline & & & & $9.00 \pm 0.74$ & $12.13 \pm 2.59^{*}$ & $7.67 \pm 0.60 \dagger$ & $\ddagger$ & & & & \\
\hline & & & & $1.38 \pm 0.47$ & $2.50 \pm 0.71$ & $0.50 \pm 0.50 \dagger$ & $\neq$ & $31.33 \pm 5.21$ & $28.00 \pm 4.00$ & $51.00 \pm 10.82^{*}, \dagger$ & $\ddagger$ \\
\hline & & & & $10.37 \pm 0.47$ & $14.63 \pm 2.95^{*}$ & $8.00 \pm 0.29 \dagger$ & $\ddagger$ & & & & \\
\hline & & & & & & & & $42.67 \pm 11.67$ & $24.50 \pm 6.81$ & $122.50 \pm 12.66^{*}, \dagger$ & $\ddagger$ \\
\hline & & & & & & & & $47.50 \pm 22.53$ & $43.83 \pm 8.25$ & $74.00 \pm 9.47^{*}, \dagger$ & $\ddagger$ \\
\hline & & & & & & & & $90.17 \pm 32.76$ & $68.33 \pm 11.11$ & $196.50 \pm 13.44^{*}, \dagger$ & $\ddagger$ \\
\hline
\end{tabular}

\section{Cholinergic cell group}

PS recovery resulted in increased numbers of cholinergic neurons expressing c-Fos in the laterodorsal and pedunculopontine tegmental nuclei, and across conditions the percent PS was significantly positively correlated with their numbers, supporting the hypothesis that cholinergic tegmental neurons are actively involved in PS generation. As confirmed here, previous studies examining single-labeled c-Fos + cells reported increases within the cholinergic cell area in association with enhanced PS (Merchant-Nancy et al., 1992; Shiromani et al., 1992; Yamuy et al., 1993). Examining dual immunostaining for c-Fos and ChAT, one study also found increases in the number of cholinergic neurons expressing c-Fos during carbachol-induced PS in cats, although, as is also the case in the present study, only a small proportion of the cholinergic cells were c-Fos + (Shiromani et al., 1996). Another more recent study failed to confirm the latter result in cats (Yamuy et al., 1998). However, because carbachol acts directly on target neurons of the cholinergic cells (VanniMercier et al., 1989; Jones, 1990), its pharmacological effect would not depend on increased activity by the cholinergic cells. In vivo electrophysiological studies have identified slow-spiking neurons as possibly cholinergic neurons and reported that these cells are PS-on cells, all discharging at higher rates during PS than during SWS and some higher during PS than during waking (Sakai and Jouvet, 1980; El Mansari et al., 1989; Steriade et al., 1990a,b; Kayama et al., 1992). Recently, juxtacellular labeling with biocytin combined with staining for NADPH-diaphorase has provided histochemical evidence that such slow-spiking neurons are cholinergic (Koyama et al., 1998). Electrophysiologically characterized neurons have moreover been shown to be inhibited by carbachol microinjections (as "Carb-I PS-on" neurons) in vivo (Sakai and Koyama, 1996), similar to the response to carbachol documented on identified cholinergic cells in vitro (Leonard and Llinas, 1994). Further evidence that cholinergic tegmental neurons are PS-on cells comes from biochemical studies showing that in the thalamus and the brainstem pontine and medullary reticular formation, to which the cholinergic tegmental neurons project (Jones and Webster, 1988; Pare et al., 1988; Jones, 1990), ACh release is greater during PS than during SWS and in the brainstem, also greater than during waking (Kodama et al., 1990,
1992; Becker et al., 1994; Williams et al., 1994; Leonard and Lydic, 1995).

PS rebound was also associated with an increase in the number of GABAergic neurons expressing c-Fos within the cholinergic cell area, and across conditions, the percent PS was positively correlated with their number. A significant proportion of neurons in the cholinergic cell area that show increased c-Fos expression in association with naturally occurring PS (Merchant-Nancy et al., 1992; Shiromani et al., 1992) and also with carbachol-induced PS (Yamuy et al., 1998) would thus, as the latter study also showed, be noncholinergic and as the present study shows, most likely GABAergic. GABAergic neurons are codistributed with the cholinergic neurons in the laterodorsal and pedunculopontine tegmental nuclei (Ford et al., 1995) and could correspond in part to other electrophysiologically identified PS-on cells, which display brief spikes and discharge rapidly (Sakai and Jouvet, 1980; El Mansari et al., 1989; Steriade et al., 1990a,b; Koyama et al., 1998). In contrast to the putative cholinergic, these presumed noncholinergic, PS-on cells are excited by carbachol microinjections ("Carb-E PS-on" neurons) in vivo (Sakai and Koyama, 1996). According to the electrophysiological study of these presumed noncholinergic Carb-E PS-on neurons and to the chemoneuroanatomical study of the GABAergic neurons in the cholinergic cell area, some PS-on GABAergic neurons could be projection neurons and project in parallel with the cholinergic neurons into the forebrain (Ford et al., 1995). Other GABAergic cells may be locally projecting neurons and innervate cell bodies or dendrites of neighboring monoaminergic neurons (Jones, 1991a,b), which they could thus inhibit during PS. In either case, they would appear to be active in parallel and perhaps also in series with the cholinergic neurons during PS.

\section{Monoaminergic cell groups}

In the dorsal and median raphe nuclei, PS recovery resulted in a decrease in the number of serotonergic cells expressing c-Fos, supporting the claim that presumed serotonergic neurons decrease or cease firing during PS (McGinty and Harper, 1976; Trulson and Jacobs, 1979). Although a recent study with carbachol-induced PS in cats found no significant difference as compared with saline-injected controls in numbers of c-Fos- 

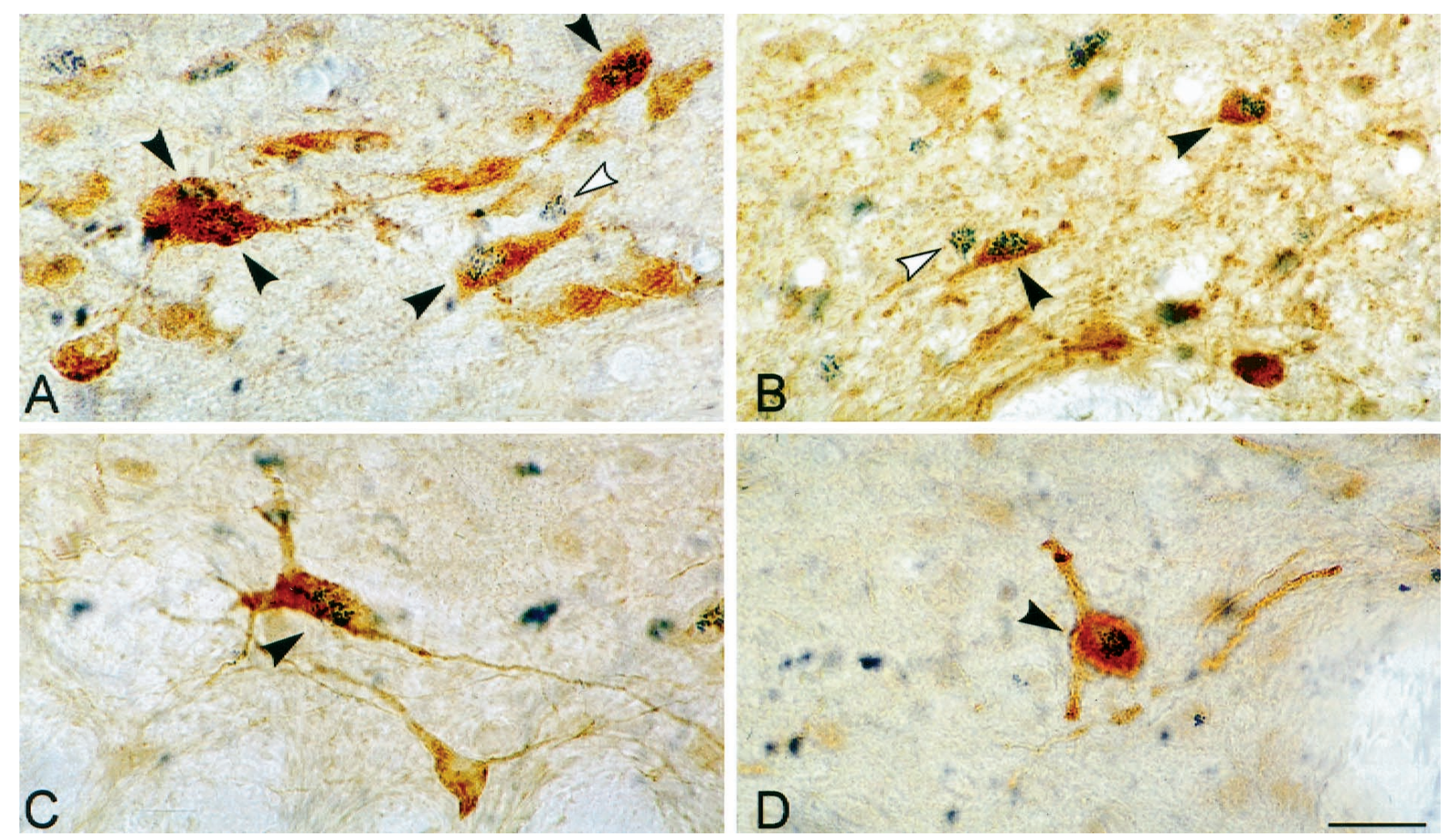

Figure 5. Photomicrographs of sections dual-immunostained for c-Fos (blue granular chromogen, BDHC) and ChAT $(A)$, GAD $(B)$, serotonin $(C)$, or TH $(D)$ (brown chromogen, DAB). Black arrowheads indicate double-labeled cells, and white arrowheads indicate examples of adjacent single-labeled c-Fos + cells. Scale, $25 \mu \mathrm{m}$.

expressing serotonergic neurons, this lack of difference was also interpreted as being caused by a lack of discharge by the serotonergic neurons during PS (Yamuy et al., 1995). Support for the cessation of serotonergic neuronal discharge during PS comes from biochemical studies that have shown a marked decrease in serotonin release during PS (Portas et al., 1998). In the present study, PS recovery also resulted in an increase in the number of GABAergic cells expressing c-Fos in the raphe and central gray, revealing potentially active inhibitory interneurons that could be responsible for the suppression of serotonergic activity. These GABAergic cells could represent a proportion of dorsal raphe nonserotonergic c-Fos-expressing cells that were increased in number with carbachol-induced PS (Yamuy et al., 1995). The GABAergic c-Fos-expressing neurons may correspond to neurons that were originally considered to be inhibitory interneurons, based on their distinct discharge properties and response to stimulation, which was reciprocal to that of the dorsal raphe serotonergic neurons (Aghajanian et al., 1978). Presumed nonserotonergic neurons have been recorded across the sleep-waking cycle, and some reported to increase their discharge during PS (Sheu et al., 1974; Shima et al., 1986; Kocsis and Vertes, 1992). GABA release measured in the dorsal raphe has been reported to be higher during PS than during SWS or waking (Nitz and Siegel, 1997a). Microperfusion with GABA $_{A}$ antagonists, bicuculline, or picrotoxin in the dorsal raphe has been reported to lift inhibition of serotonergic neurons during sleep (Levine and Jacobs, 1992) and also to decrease PS (Nitz and Siegel, 1997a). In summary, within the raphe, the inverse correlations of percent PS with GABAergic versus serotonergic c-Fos-expressing neurons suggests together with other evidence, that GABAergic raphe neu- rons are PS-on cells, which may be partly responsible for the important inhibition of codistributed serotonergic PS-off cells.

In the locus coeruleus and subcoeruleus, there was a significant decrease in the numbers of noradrenergic c-Fos-expressing cells during PS recovery as compared with deprivation and a significant negative correlation in these numbers with the percent PS across conditions. These results support the claim that noradrenergic locus coeruleus neurons cease firing during PS and may accordingly play a permissive role in PS generation (Hobson et al., 1975; McCarley and Hobson, 1975; Aston-Jones and Bloom, 1981a). With carbachol-induced PS in cats, no significant difference was documented in c-Fos-expressing noradrenergic neurons relative to controls (Yamuy et al., 1995). In the present study, PS recovery resulted in an increase in the number of c-Fosexpressing GABAergic neurons, which were located in the vicinity of the noradrenergic cells and which could thus act as local inhibitory neurons. These GABAergic cells could represent a proportion of the non-noradrenergic c-Fos-expressing cells in the locus coeruleus region that were found to be increased with carbachol-induced PS in cats (Yamuy et al., 1995). In support of increased activity during PS of GABAergic neurons innervating the locus coeruleus, biochemical studies have found greater release of GABA in the locus coeruleus during PS than during SWS or waking (Nitz and Siegel, 1997b). Moreover, the cessation of discharge by locus coeruleus neurons during this state can be reversed by microinjection of the $\mathrm{GABA}_{\mathrm{A}}$ antagonist bicuculline (Gervasoni et al., 1998), which also results in a decrease in PS (Kaur et al., 1997). In summary, the present results showing inverse correlations of PS with GABAergic versus noradrenergic 

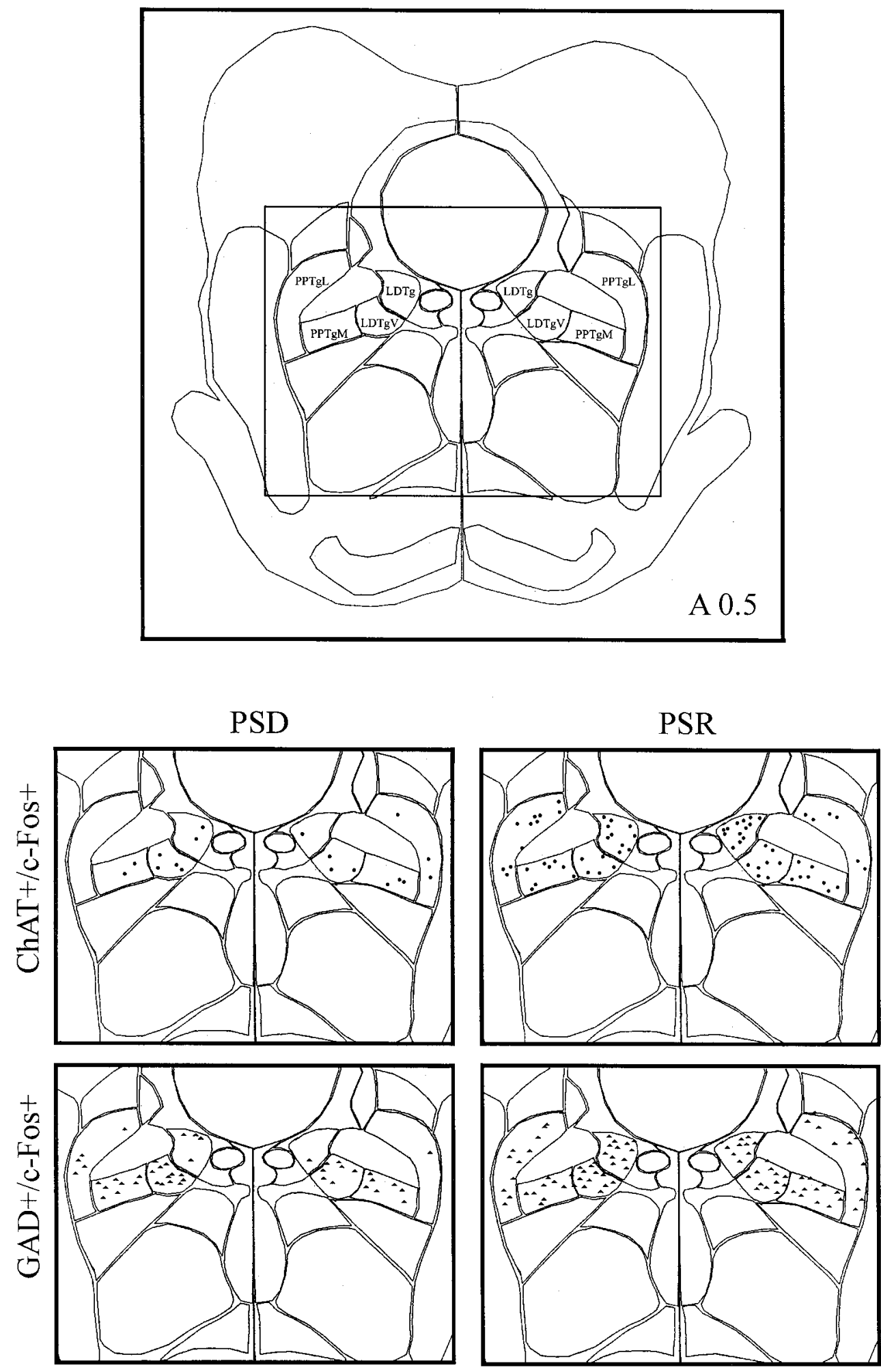

Figure 6. Computerized atlas figure through the pontomesencephalic tegmentum $(\sim \mathrm{A} 0.5)$ showing the cholinergic cell group (top) where $\mathrm{ChAT}+/ \mathrm{c}$ Fos + cells (circles) and GAD +/c-Fos + cells (triangles) were mapped (bottom) in representative animals from PSD (left) and PSR (right) groups. Note apparent increase in ChAT $+/ \mathrm{c}-\mathrm{Fos}+$ cells and $\mathrm{GAD}+/ \mathrm{c}-\mathrm{Fos}+$ cells in the PSR condition compared with the PSD condition. $L D T g$, Laterodorsal tegmental nucleus; $L D T g V$, laterodorsal tegmental nucleus, ventral part; $P P T g M$, pedunculopontine tegmental nucleus, medial part; $P P T g L$, pedunculopontine tegmental nucleus.
c-Fos-expressing neurons provide evidence that GABAergic neurons are active during PS and may be responsible for the important inhibition of adjacent noradrenergic neurons during PS.

\section{Interaction between cell groups}

The present results substantiate the concept that cholinergic tegmental neurons are actively involved, as PS-on cells, whereas monoaminergic neurons may be permissively involved, as PS-off cells, in PS generation (Sakai, 1988; McCarley et al., 1995). Given pharmacological evidence that serotonin and noradrenaline inhibit cholinergic tegmental neurons (Luebke et al., 1992; Williams and Reiner, 1993; Leonard and Llinas, 1994; Leonard et al., 1995), the monoaminergic neurons could tonically inhibit cholinergic neurons during the waking state, rendering them PS-on/ 


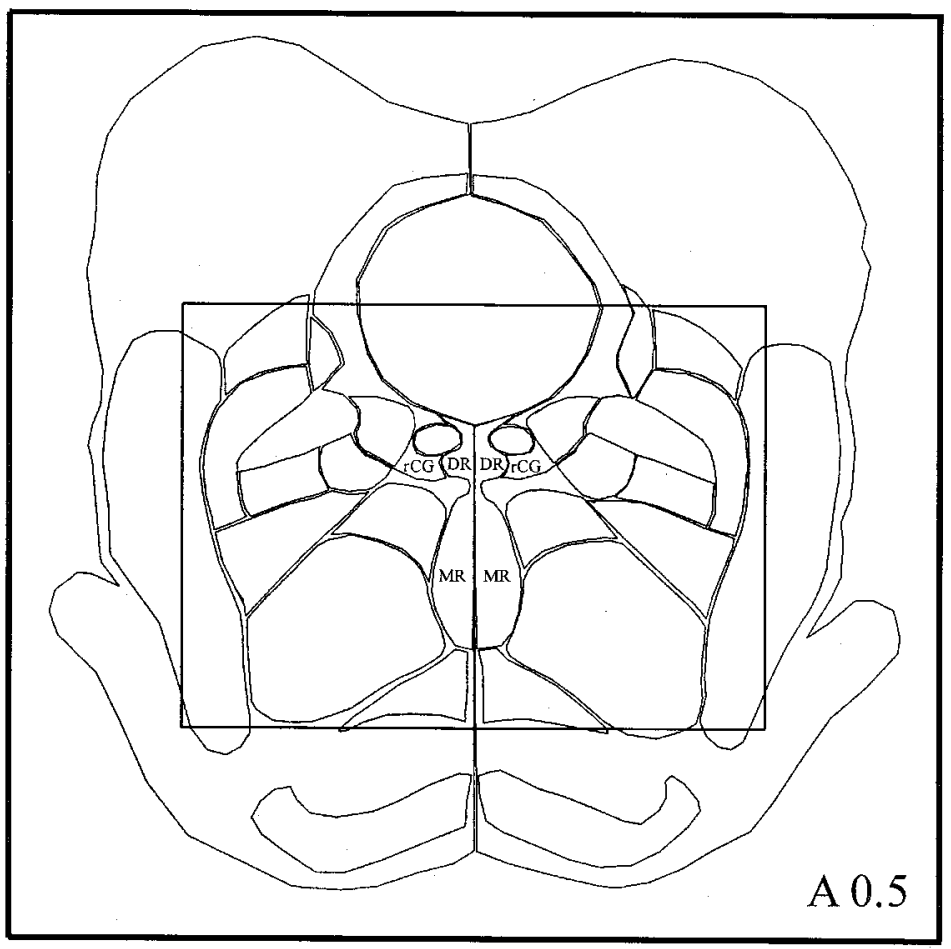

Figure 7. Computerized atlas figure through the pontomesencephalic tegmentum $(\sim \mathrm{A} 0.5)$ showing serotonergic cell group and surrounding rostral central gray area (top) where $\mathrm{Ser}+/ \mathrm{c}$ Fos + cells (asterisks) and GAD $+/ \mathrm{c}-$ Fos + cells (triangles) were mapped (bottom) in representative animals from the PSD (left) and PSR (right) groups. Note the apparent decrease in Ser $+/ c-F o s+$ cells and increase in GAD $+/ \mathrm{c}-$ Fos + cells in the PSR condition compared with the PSD condition. $r C G$, Rostral central gray; $D R$, dorsal raphe nucleus; $M R$, median raphe nucleus.
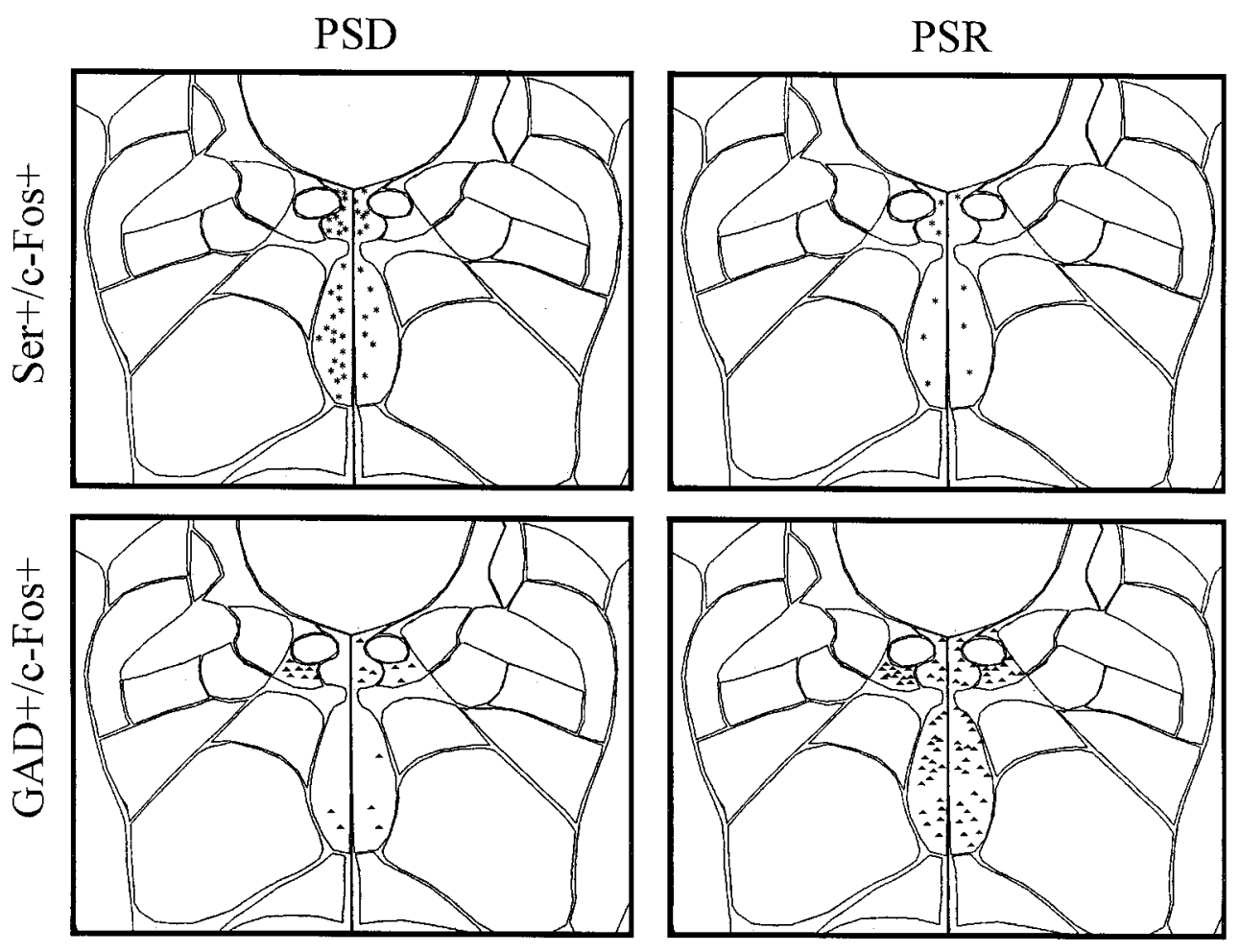

Wake-off cells. The reciprocal increase in noradrenergic locus coeruleus c-Fos-expressing neurons and decrease in cholinergic laterodorsal tegmental c-Fos-expressing neurons during PS deprivation could reflect such an influence in the present study, as well as confirming the role of noradrenergic neurons in behavioral and cortical arousal and stress (Foote et al., 1980; Aston-Jones and Bloom, 1981a,b; Abercrombie and Jacobs, 1987; Jones, 1991c;
Pezzone et al., 1993; Tononi et al., 1994). However, in view of the reported high levels of $\mathrm{ACh}$ release in the thalamus during waking (Williams et al., 1994), it is unlikely that all cholinergic tegmental neurons are tonically inhibited during this state. Another possibility is that a subset of cholinergic neurons having particular projections are PS-on/Wake-off cells, such as those projecting into the brainstem (Jones, 1990), where ACh release is 


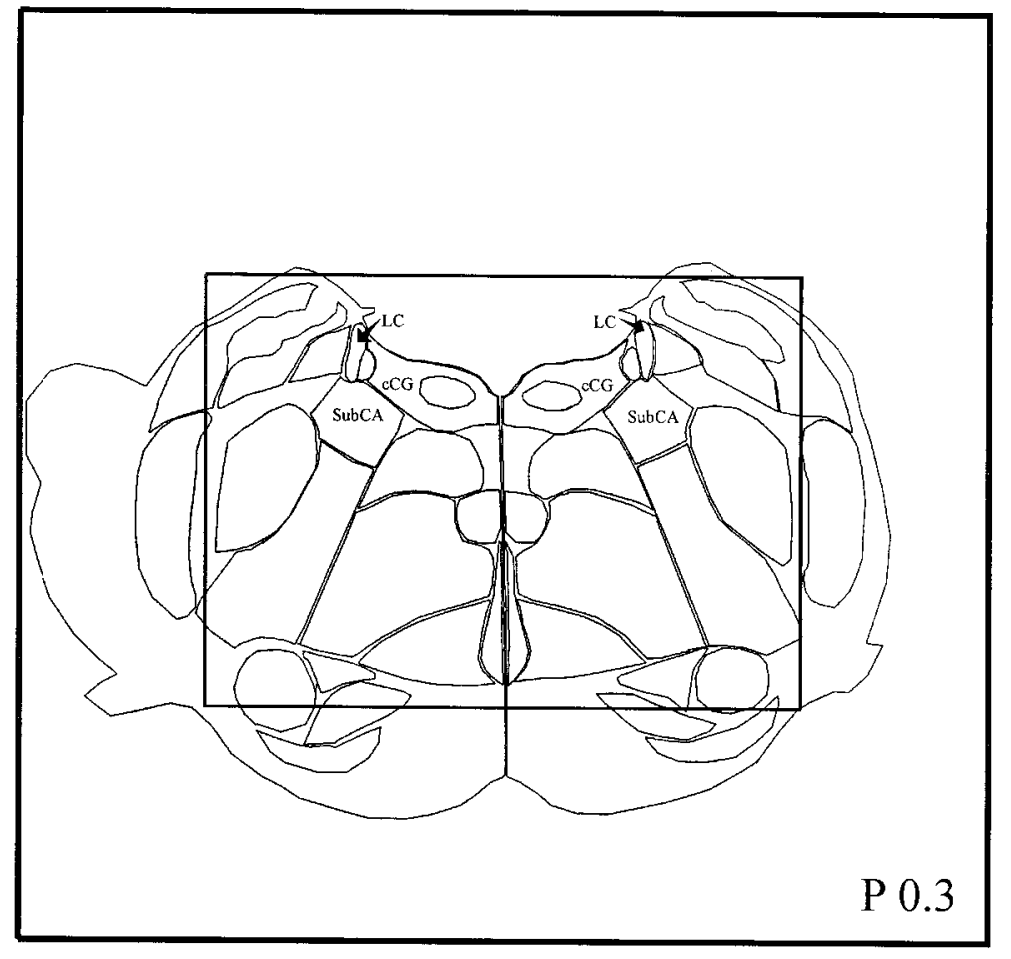

PSD
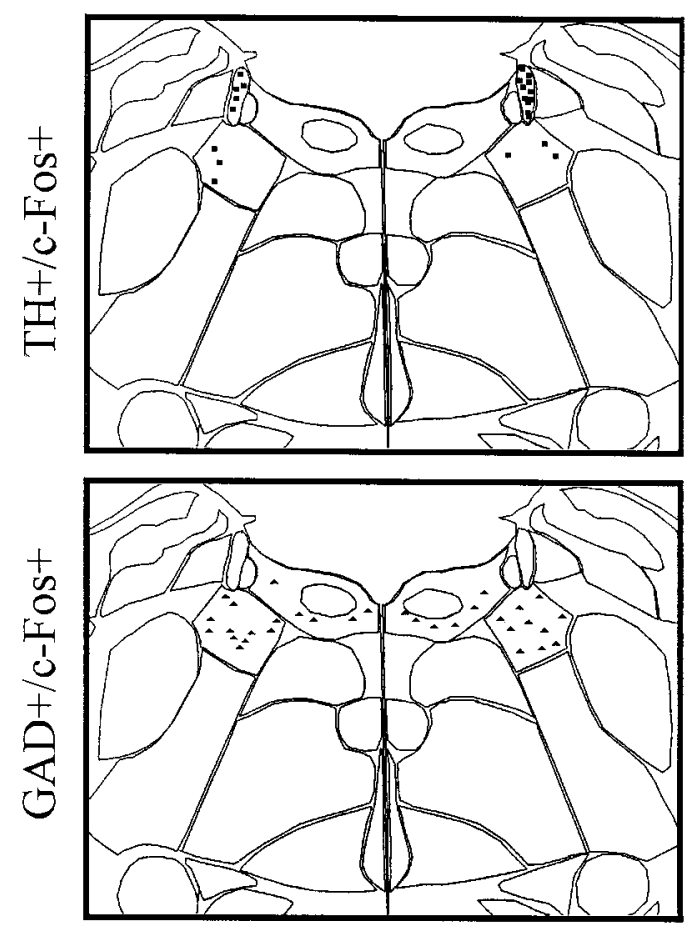

\section{PSR}
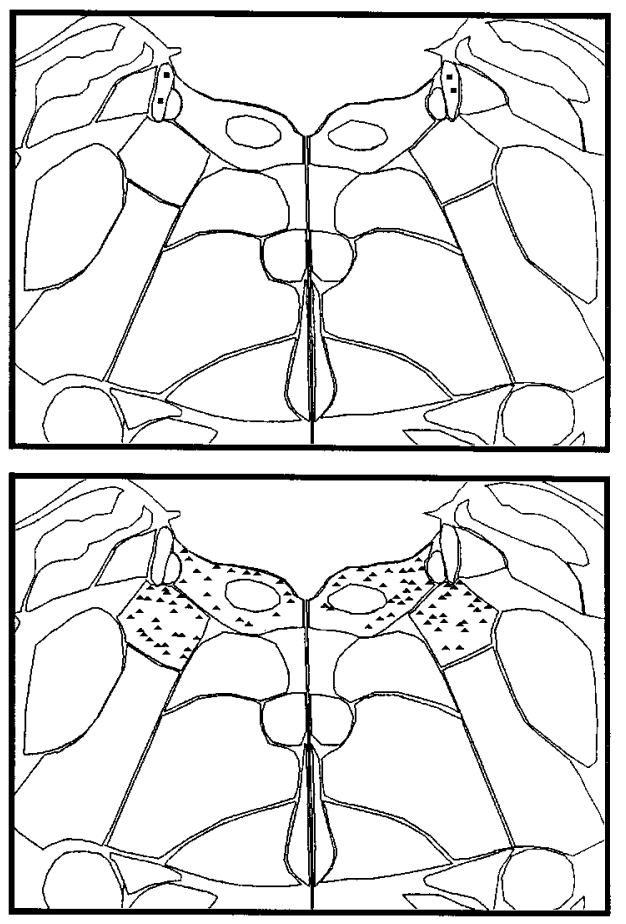

Figure 8. Computerized atlas figure through the pontomesencephalic tegmentum $(\sim \mathrm{P} 0.3)$ showing noradrenergic cell group and surrounding caudal central gray (top) where $\mathrm{TH}+/ \mathrm{c}-$ Fos + cells (squares) and GAD $+/ c-$ Fos + cells (triangles) were mapped (bottom) in representative animals from PSD (left) and PSR (right) groups. Note the apparent decrease in $\mathrm{TH}+/ \mathrm{c}-\mathrm{Fos}+$ cells and increase in $\mathrm{GAD}+/ \mathrm{c}-\mathrm{Fos}+$ cells in the PSR condition compared with the PSD condition. $c C G$, Caudal central gray; $L C$, locus coeruleus; $S u b C A$, subcoeruleus nucleus, $\alpha$ part. greater during PS than during waking (Kodama et al., 1990, 1992). Electrophysiological evidence has recently been presented that there are two subsets of putative cholinergic neurons, one that is PS-on/Wake-off and inhibited by serotonin, and another that is PS-on/Wake-on and unaffected by serotonin (Thakkar et al., 1998). The present results would support the hypothesis that a subset of cholinergic neurons may be selectively active during
PS and reciprocally related in their activity to monoaminergic neurons across the sleep-waking cycle.

In addition, the present results indicate that GABAergic neurons that are codistributed with cholinergic and monoaminergic neurons in the pontomesencephalic tegmentum are also active during PS and could accordingly, as PS-on cells, inhibit the monoaminergic PS-off cells. Simultaneous unit recordings of pu- 

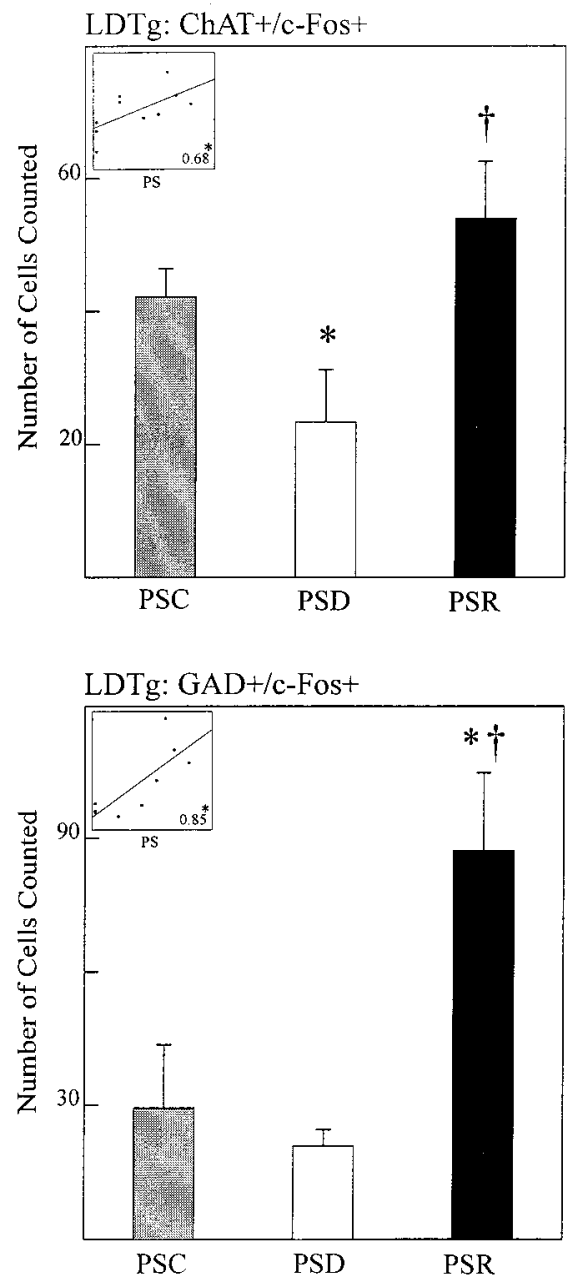
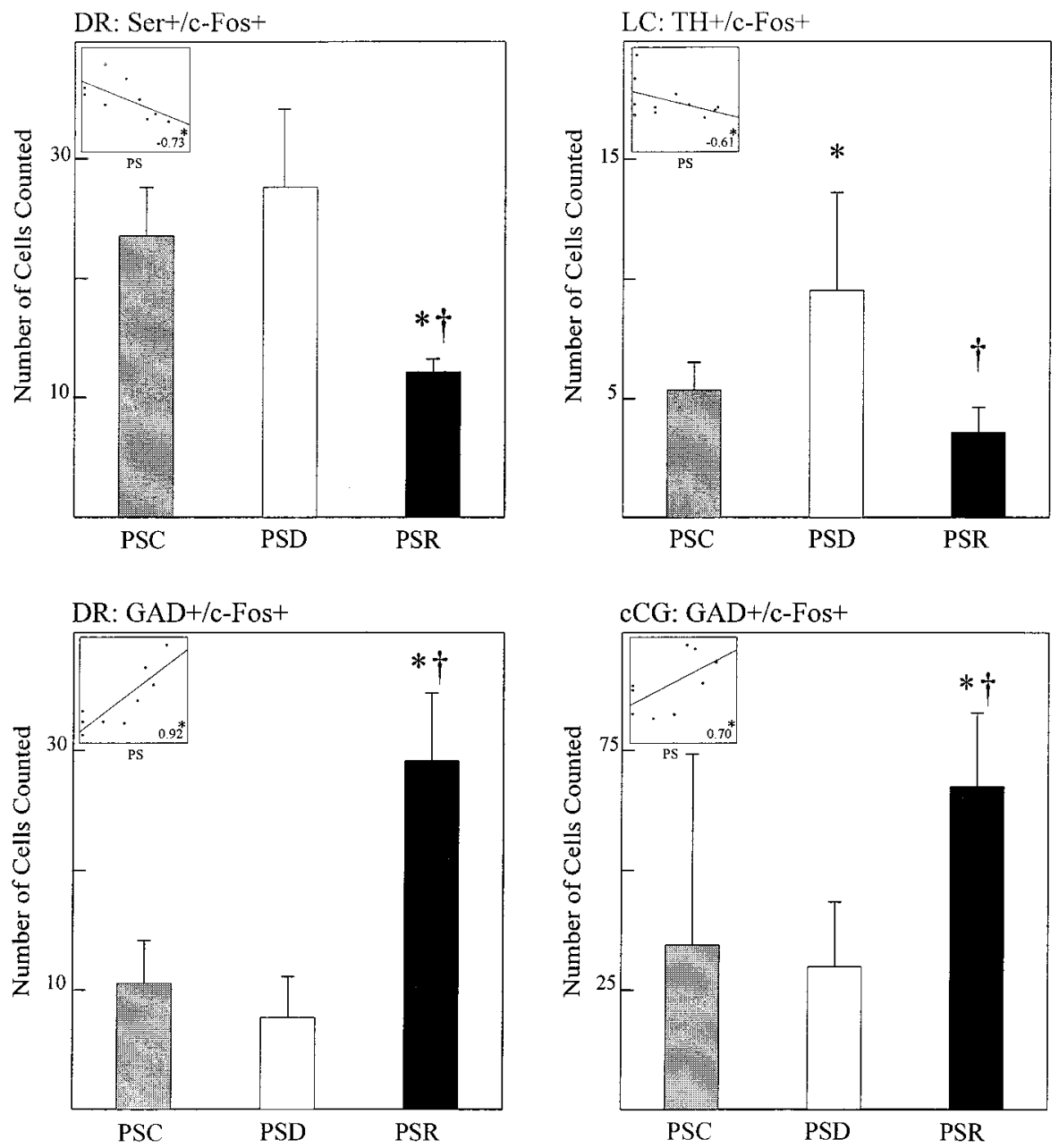

Figure 9. Numbers of ChAT $+/ \mathrm{c}-$ Fos + and GAD $+/ \mathrm{c}-$ Fos + neurons in the LDTg, Ser $+/ \mathrm{c}-$ Fos + , and GAD $+/ \mathrm{c}-$ Fos + neurons in the DR, and $\mathrm{TH}+/ \mathrm{c}-\mathrm{Fos}+$ neurons and GAD $+/ \mathrm{c}-\mathrm{Fos}+$ neurons in the LC and neighboring cCG, respectively, for the three different groups, PSC, PSD, and PSR. As according to the statistics detailed in Table 2, there was a significant main effect of condition in every case shown. According to post hoc tests, there were significant differences between individual conditions as indicated: PSR or PSD versus PSC, ${ }^{*} p \leq 0.05$; PSR versus PSD, $\dagger p \leq 0.05$. The inserts in the top left corners show linear regression plots and coefficients of cell numbers with the percent of PS across conditions. The scale of the $x$-axis is consistent for all boxes and represents percent PS (0-40\%), as indicated. The scales of the $y$-axes correspond to the number of cells, as indicated in the respective full scale $y$-axis for each cell type and nucleus. Correlations between percent time spent in PS and the number of double-labeled cells in each nucleus were examined by multiple linear regression with animal as a covariate $\left({ }^{*} p \leq 0.05, \mathrm{df}=11\right)$. See Table 2 and Materials and Methods for other details.

tative cholinergic PS-on and monoaminergic PS-off cells during transitions into and out of PS have revealed mirror image changes in their discharge, such as to suggest a mutual inhibitory relationship between them (Sakai, 1988). Because ACh is excitatory to monoaminergic neurons (Egan and North, 1986; Li et al., 1998), the cholinergic cells could only effect such an inhibition via local interneurons (Jones, 1991b). Reported putative noncholinergic PS-on cells that are excited by carbachol (Sakai and Koyama, 1996) could correspond in part to such GABAergic interneurons. GABAergic neurons in the pontomesencephalic tegmentum would accordingly play an integral role in the generation of PS.

\section{REFERENCES}

Abercrombie ED, Jacobs BL (1987) Single-unit response of noradrenergic neurons in the locus coeruleus of freely moving cats. I. Acutely presented stressful and nonstressful stimuli. J Neurosci 7:2837-2843.

Aghajanian GK, Wang RY, Barban J (1978) Serotonergic and nonserotonergic neurons of the dorsal raphe: reciprocal changes in firing induced by peripheral nerve stimulation. Brain Res 153:169-175.

Aston-Jones G, Bloom FE (1981a) Activity of norepinephrine- containing locus coeruleus neurons in behaving rats anticipates fluctuations in the sleep-waking cycle. J Neurosci 1:876-886.

Aston-Jones G, Bloom FE (1981b) Norepinephrine-containing locus coeruleus neurons in behaving rats exhibit pronounced responses to non-noxious environmental stimuli. J Neurosci 1:887-900.

Becker L, Baghdoyan HA, Lydic R (1994) Acetylcholine (ACh) release in the medial pontine reticular formation (mPRF) increases during natural rapid eye movement (REM) sleep. Soc Neurosci Abstr 20:82.

Chen X, Herbert J (1995) Regional changes in c-fos expression in the basal forebrain and brainstem during adaptation to repeated stress: correlations with cardiovascular, hypothermic and endocrine responses. Neuroscience 64:675-685.

Cullinan WE, Herman JP, Battaglia DF, Akil H, Watson SJ (1995) Pattern and time course of immediate early gene expression in rat brain following acute stress. Neuroscience 64:477-505.

Domino EF, Yamamoto K, Dren AT (1968) Role of cholinergic mechanisms in states of wakefulness and sleep. Prog Brain Res 28:113-133.

Dragunow M, Faull R (1989) The use of c-fos as a metabolic marker in neuronal pathway tracing. J Neurosci Methods 29:261-265.

Egan TM, North RA (1986) Actions of acetylcholine and nicotine on rat locus coeruleus neurons in vitro. Neuroscience 19:565-571.

El Mansari M, Sakai M, Jouvet M (1989) Unitary characteristics of 
presumptive cholinergic tegmental neurons during the sleep-waking cycle in freely moving cats. Exp Brain Res 76:519-529.

Foote SL, Aston-Jones G, Bloom FE (1980) Impulse activity of locus coeruleus neurons in awake rats and monkeys is a function of sensory stimulation and arousal. Proc Natl Acad Sci USA 77:3033-3037.

Ford B, Holmes C, Mainville L, Jones BE (1995) GABAergic neurons in the rat pontomesencephalic tegmentum. Codistribution with cholinergic and other tegmental neurons projecting to the posterior lateral hypothalamus. J Comp Neurol 363:177-196.

George R, Haslett W, Jenden D (1964) A cholinergic mechanism in the brainstem reticular formation: induction of paradoxical sleep. Int J Neuropharmacol 3:541-552.

Gervasoni D, Darracq L, Fort P, Souliere F, Chouvet G, Luppi P-H (1998) Electrophysiological evidence that noradrenergic neurons of the rat locus coeruleus are tonically inhibited by GABA during sleep. Eur J Neurosci 10:964-970.

Gritti I, Mainville L, Jones BE (1993) Codistribution of GABA- with acetylcholine-synthesizing neurons in the basal forebrain of the rat. J Comp Neurol 329:438-457.

Gritti I, Mainville L, Mancia M, Jones BE (1997) GABAergic and other non-cholinergic basal forebrain neurons project together with cholinergic neurons to meso- and iso-cortex in the rat. J Comp Neurol 383:163-177.

Hobson JA, McCarley RW, Wyzinski PW (1975) Sleep cycle oscillation: reciprocal discharge by two brainstem neuronal groups. Science 189:55-58.

Jones BE (1990) Immunohistochemical study of choline acetyl transferase-immunoreactive processes and cells innervating the pontomedullary reticular formation. J Comp Neurol 295:485-514.

Jones BE (1991a) Noradrenergic locus coeruleus neurons: their distant connections and their relationship to neighboring-including cholinergic and GABAergic-neurons of the central gray and reticular formation. In: Neurobiology of the locus coeruleus. Progress in brain research, Vol 85 (Barnes C, Pompeiano O, eds), pp 15-30. Amsterdam: Elsevier.

Jones BE (1991b) Paradoxical sleep and its chemical/structural substrates in the brain. Neuroscience 40:637-656.

Jones BE (1991c) The role of noradrenergic locus coeruleus neurons and neighboring cholinergic neurons of the pontomesencephalic tegmentum in sleep-wake states. In: Neurobiology of the locus coeruleus. Progress in brain research, Vol 85 (Barnes C, Pompeiano O, eds), pp 532-543. Amsterdam: Elsevier.

Jones BE (1993) The organization of central cholinergic systems and their functional importance in sleep-waking states. In: Cholinergic function and dysfunction. Progress in brain research, Vol 98 (Cuello AC, ed), pp 61-71. Amsterdam: Elsevier.

Jones BE (1995) Reticular formation. Cytoarchitecture, transmitters and projections. In: The rat nervous system, Ed 2, (Paxinos G, ed), pp 155-171. New South Wales: Academic Press Australia.

Jones BE, Beaudet A (1987) Distribution of acetylcholine and catecholamine neurons in the cat brain stem studied by choline acetyltransferase and tyrosine hydroxylase immunohistochemistry. J Comp Neurol 261:15-32.

Jones BE, Webster HH (1988) Neurotoxic lesions of the dorsolateral pontomesencephalic tegmentum: cholinergic cell area in the cat. I. Effects upon the cholinergic innervation of the brain. Brain Res 451:13-32.

Jouvet M (1962) Recherches sur les structures nerveuses et les mecanismes responsables des differentes phases du sommeil physiologique. Arch Ital Biol 100:125-206.

Jouvet M (1972) The role of monoamines and acetylcholine-containing neurons in the regulation of the sleep-waking cycle. Ergeb Physiol 64:165-307.

Karczmar AG, Longo VG, Scotti de Carolis A (1970) A pharmacological model of paradoxical sleep: the role of cholinergic and monoamine systems. Physiol Behav 5:175-182.

Kaur S, Saxena RN, Mallick BN (1997) GABA in locus coeruleus regulates spontaneous rapid eye movement sleep by acting on $\mathrm{GABA}_{\mathrm{A}}$ receptors in freely moving rats. Neurosci Lett 223:105-108.

Kayama Y, Ohta M, Jodo E (1992) Firing of "possibly" cholinergic neurons in the rat laterodorsal tegmental nucleus during sleep and wakefulness. Brain Res 569:210-220.

Kocsis B, Vertes RP (1992) Dorsal raphe neurons: synchronous discharge with the theta rhythm of the hippocampus in the freely behaving rat. J Neurophysiol 68:1463-1467.

Kodama T, Takahashi Y, Honda Y (1990) Enhancement of acetylcho- line release during paradoxical sleep in the dorsal tegmental field of the cat brain stem. Neurosci Lett 114:277-282.

Kodama T, Lai YY, Siegel JM (1992) Enhancement of acetylcholine release during REM sleep in the caudomedial medulla as measured by in vivo microdialysis. Brain Res 580:348-350.

Koyama Y, Honda T, Kusakabe M, Kayama Y, Sugiura Y (1998) In vivo electrophysiological distinction of histochemically identified cholinergic neurons using extracellular recording and labelling in rat laterodorsal tegmental nucleus. Neuroscience 83:1105-1112.

Leonard CS, Llinas R (1994) Serotonergic and cholinergic inhibition of mesopontine cholinergic neurons controlling REM sleep: an in vitro electrophysiological study. Neuroscience 59:309-330.

Leonard CS, Rao S, Sanchez RM (1995) Patterns of neuromodulation and the nitric oxide signaling pathway in mesopontine cholinergic neurons. Semin Neurosci 7:319-328.

Leonard TO, Lydic R (1995) Nitric oxide synthase inhibition decreases pontine acetylcholine release. NeuroReport 6:1525-1529.

Levine ES, Jacobs BL (1992) Neurochemical afferents controlling the activity of serotonergic neurons in the dorsal raphe nucleus: microiontophoretic studies in the awake cat. J Neurosci 12:4037-4044.

Li X, Rainnie DG, McCarley RW, Greene RW (1998) Presynaptic nicotinic receptors facilitate monoaminergic transmission. J Neurosci 18:1904-1912.

Luebke JI, Greene RW, Semba K, Kamondi A, McCarley RW, Reiner PB (1992) Serotonin hyperpolarizes cholinergic low-threshold burst neurons in the rat laterodorsal tegmental nucleus in vitro. Proc Natl Acad Sci USA 89:743-747.

Maloney KJ, Jones BE (1997) C-Fos expression in cholinergic, GABAergic and monoaminergic cell groups during paradoxical sleep deprivation and recovery. Soc Neurosci Abstr 23:2131.

Maloney KJ, Cape EG, Gotman J, Jones BE (1997) High frequency gamma electroencephalogram activity in association with sleep-wake states and spontaneous behaviors in the rat. Neuroscience 76:541-555.

McCarley RW, Hobson JA (1975) Neuronal excitability modulation over the sleep cycle: a structural and mathematical model. Science 189:58-60.

McCarley RW, Greene RW, Rainnie D, Portas CM (1995) Brainstem neuromodulation and REM sleep. The Neurosciences 7:341-354.

McGinty D, Harper RM (1976) Dorsal raphe neurons: depression of firing during sleep in cats. Brain Res 101:569-575.

Mendelson WB (1974) The flower pot technique of rapid eye movement sleep deprivation. Pharmacol Biochem Behav 2:553-556.

Merchant-Nancy H, Vazquez J, Aguilar-Roblero R, Drucker-Colin R (1992) c-fos proto-oncogene changes in relation to REM sleep duration. Brain Res 579:342-346.

Mesulam M-M, Mufson EJ, Wainer BH, Levey AI (1983) Central cholinergic pathways in the rat: an overview based on an alternative nomenclature (Ch1-Ch6). Neuroscience 10:1185-1201.

Morgan JI, Curran T (1986) Role of ion flux in the control of c-fos expression. Nature 322:552-555.

Nitz D, Siegel J (1997a) GABA release in the dorsal raphe nucleus: role in the control of REM sleep. Am J Physiol 273:R451-R455.

Nitz D, Siegel JM (1997b) GABA release in the locus coeruleus as a function of sleep/wake state. Neuroscience 1997:795-801.

Pare E, Smith Y, Parent A, Steriade M (1988) Projections of brainstem core cholinergic and non-cholinergic neurons of cat to intralaminar and reticular thalamic nuclei. Neuroscience 25:69-86.

Paxinos G, Watson C (1986) The rat brain in stereotaxic coordinates. Sydney: Academic

Pezzone MA, Lee W-S, Hoffman GE, Pezzone KM, Rabin BS (1993) Activation of brainstem catecholaminergic neurons by conditioned and unconditioned aversive stimuli as revealed by c-Fos immunoreactivity. Brain Res 608:310-318.

Portas CM, Bjorvatn B, Fagerland S, Gronli J, Mundal V, Sorensen E, Ursin R (1998) On-line detection of extracellular levels of serotonin in dorsal raphe nucleus and frontal cortex over the sleep/wake cycle in the freely moving rat. Neuroscience 83:807-814.

Sakai K (1988) Executive neurons of paradoxical sleep. Arch Ital Biol 126:239-257.

Sakai K, Jouvet M (1980) Brain stem PGO-on cells projecting directly to the cat dorsal lateral geniculate nucleus. Brain Res 194:500-505.

Sakai K, Koyama Y (1996) Are there cholinergic and non-cholinergic paradoxical sleep-on neurones in the pons. NeuroReport 7:2449-2453.

Sheu Y-S, Nelson JP, Bloom FE (1974) Discharge patterns of cat raphe neurons during sleep and waking. Brain Res 73:263-276. 
Shima K, Nakahama H, Yamamoto M (1986) Firing properties of two types of nucleus raphe dorsalis neurons during the sleep-waking cycle and their responses to sensory stimuli. Brain Res 399:317-326.

Shiromani PJ, Kilduff TS, Bloom FE, McCarley RW (1992) Cholinergically induced REM sleep triggers Fos-like immunoreactivity in dorsolateral pontine regions associated with REM sleep. Brain Res 580:351-357.

Shiromani PJ, Winston S, McCarley RW (1996) Pontine cholinergic neurons show Fos-like immunoreactivity associated with cholinergically induced REM sleep. Mol Brain Res 38:77-84.

Steriade M, Datta S, Pare D, Oakson G, Curro Dossi R (1990a) Neuronal activities in brain-stem cholinergic nuclei related to tonic activation processes in thalamocortical systems. J Neurosci 10:2541-2559.

Steriade M, Pare D, Datta S, Oakson G, Dossi RC (1990b) Different cellular types in mesopontine cholinergic nuclei related to pontogeniculo-occipital waves. J Neurosci 10:2560-2579.

Sternberger LA (1979) Immunocytochemistry. New York: Wiley.

Thakkar MM, Strecker RE, McCarley RW (1998) Behavioral state control through differential serotonergic inhibition in the mesopontine cholinergic nuclei: a simultaneous unit recording and microdialysis study. J Neurosci 18:5490-5497.

Tononi G, Pompeiano M, Cirelli C (1994) The locus coeruleus and immediate-early genes in spontaneous and forced wakefulness. Brain Res Bull 35:589-596.
Trulson ME, Jacobs BL (1979) Raphe unit activity in freely moving cats: correlation with level of behavioral arousal. Brain Res 163:135-150.

Vanni-Mercier G, Sakai K, Lin J-S, Jouvet M (1989) Mapping of cholinoceptive brainstem structures responsible for the generation of paradoxical sleep in the cat. Arch Ital Biol 127:133-164.

Webster HH, Jones BE (1988) Neurotoxic lesions of the dorsolateral pontomesencephalic tegmentum-cholinergic cell area in the cat. II. Effects upon sleep-waking states. Brain Res 458:285-302.

Williams JA, Comisarow J, Day J, Fibiger HC, Reiner PB (1994) Statedependent release of acetylcholine in rat thalamus measured by in vivo microdialysis. J Neurosci 14:5236-5242.

Williams JA, Reiner PB (1993) Noradrenaline hyperpolarizes identified rat mesopontine cholinergic neurons in vitro. J Neurosci 13:3878-3883.

Yamuy J, Mancillas JR, Morales FR, Chase MH (1993) C-fos expression in the pons and medulla of the cat during carbachol-induced active sleep. J Neurosci 13:2703-2718.

Yamuy J, Sampogna S, Lopez-Rodriguez F, Luppi PH, Morales FR, Chase MH (1995) Fos and serotonin immunoreactivity in the raphe nuclei of the cat during carbachol-induced active sleep: a doublelabeling study. Neuroscience 67:211-223.

Yamuy J, Sampogna S, Morales FR, Chase MH (1998) c-fos expression in mesopontine noradrenergic and cholinergic neurons of the cat during carbachol induced active sleep: a double-labeling study. Sleep Res Online 1:28-40, http://www.sro.org/1998/Yamuy/28/. 